\title{
An Experimental and Modeling Study of the Flammability of Fuel Tank Headspace Vapors from Ethanol/Gasoline Fuels
}

Phase 2: Evaluations of Field Samples and Laboratory Blends

D.P. Gardiner, M.F. Bardon, and M. LaViolette Nexum Research Corporation Kingston, Ontario, Canada

Subcontract Report NREL/SR-540-47819 April 2010 


\section{An Experimental and Modeling Study of the Flammability of Fuel Tank Headspace Vapors from Ethanol/Gasoline Fuels}

\section{Phase 2: Evaluations of Field Samples and Laboratory Blends}

D.P. Gardiner, M.F. Bardon, and M. LaViolette

Nexum Research Corporation

Kingston, Ontario, Canada

NREL Technical Monitor (Phase 1): M. Melendez

NREL Technical Monitor (Phase 2): Y. Coy

Prepared under Subcontract No. XCl-5-55505-01

Subcontract Period of Performance (Phase 1): August 2005 to December 2008

Subcontract Period of Performance (Phase 2): May 2009 to December 2009

National Renewable Energy Laboratory

1617 Cole Boulevard, Golden, Colorado 80401-3393

303-275-3000 • www.nrel.gov

NREL is a national laboratory of the U.S. Department of Energy

Office of Energy Efficiency and Renewable Energy

Operated by the Alliance for Sustainable Energy, LLC

Contract No. DE-AC36-08-GO28308

Subcontract Report NREL/SR-540-47819

April 2010

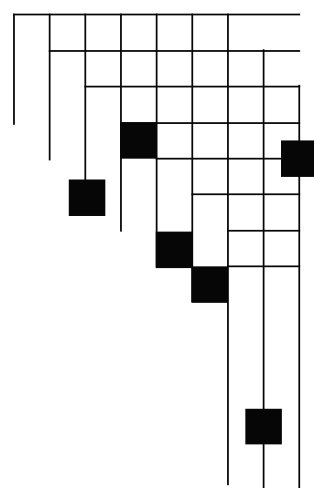




\section{NOTICE}

This report was prepared as an account of work sponsored by an agency of the United States government. Neither the United States government nor any agency thereof, nor any of their employees, makes any warranty, express or implied, or assumes any legal liability or responsibility for the accuracy, completeness, or usefulness of any information, apparatus, product, or process disclosed, or represents that its use would not infringe privately owned rights. Reference herein to any specific commercial product, process, or service by trade name, trademark, manufacturer, or otherwise does not necessarily constitute or imply its endorsement, recommendation, or favoring by the United States government or any agency thereof. The views and opinions of authors expressed herein do not necessarily state or reflect those of the United States government or any agency thereof.

Available electronically at http://www.osti.gov/bridge

Available for a processing fee to U.S. Department of Energy and its contractors, in paper, from:

U.S. Department of Energy

Office of Scientific and Technical Information

P.O. Box 62

Oak Ridge, TN 37831-0062

phone: 865.576 .8401

fax: 865.576 .5728

email: mailto:reports@adonis.osti.gov

Available for sale to the public, in paper, from:

U.S. Department of Commerce

National Technical Information Service

5285 Port Royal Road

Springfield, VA 22161

phone: 800.553 .6847

fax: 703.605.6900

email: orders@ntis.fedworld.gov

online ordering: http://www.ntis.gov/ordering.htm 


\section{Executive Summary}

\section{Background}

The flammability of a fuel blend in the head space of a storage tank is controlled by the vapor pressure of the blend. Conventional gasolines are so volatile that the headspace vapors are normally too rich to sustain combustion at most ambient temperatures. Only under very cold conditions does the vapor-air mixture in the tank become flammable.

Because of its different vapor pressure and stoichiometry, pure ethanol produces vapor-air mixtures in the tank that are flammable over a wide range of ambient temperatures. Blends of ethanol and gasoline form non-ideal mixtures in which the gasoline components render the vapor-air mixture in a tank too rich for combustion at warm temperatures. Like gasoline, as temperature drops, the vapor-air mixture becomes leaner and eventually falls into the flammable region. However, the mixture becomes flammable at higher temperatures than conventional gasoline and so presents a greater hazard if a suitable ignition source is present.

\section{Objectives of the Work Reported}

This project comprised an experimental study to measure the flammability of fuel vapors at low ambient temperatures and further development of a mathematical model to predict the temperatures at which flammable vapors were likely to form.

In the current project, two sets of fuels were investigated. The first set consisted of "real world" fuel samples obtained from refuelling stations, which are referred to as "field samples" throughout this report. These samples included E85 blends, as well as low- and mid-level blends containing approximately $10-30 \%$ ethanol. Investigations involving these fuels were intended to provide information about the possibility of flammable mixtures forming with the fuels that are currently available.

The second set of fuels (provided by Marathon Petroleum Company) was produced in a laboratory to systematically investigate the effects of varying ethanol content on the volatility and flammability of the resulting blends. These fuels were produced by blending denatured ethanol with varying percentages of a single type of gasoline. The gasoline used for the blends had properties that were representative of a typical winter grade fuel. Investigations involving these fuels were intended to provide information to guide future fuel specifications. Such specifications could be developed based upon knowledge of the compromise between avoiding flammable mixtures at low ambient temperatures and maximizing the ethanol content of the fuel.

\section{Principal Results}

1. Both of the E85 field samples that were tested had vapor pressure values well below the minimum Class 3 specifications of ASTM D 5798-09. One of these fuels produced flammable vapors over the entire Class 3 temperature range $\left(-5^{\circ} \mathrm{C}\right.$ and below). The other fuel produced flammable vapors at $-10^{\circ} \mathrm{C}$ and below. These results indicate that at least some of the ethanol fuels that are currently available when and where Class 3 conditions exist are likely to produce flammable vapors within the ambient temperature range where they are used. 
2. Two mid-level ethanol blends (E20 and E30) were tested. These field samples were produced by a blender pump that mixed E10 (the base gasoline available at that location) with E85. No significant differences could be measured between vapor flammability limits of the E20-E30 samples and the E10 sample they were produced from. These results indicate that mid-level blends in this range are unlikely to significantly increase the risk of producing flammable vapors over that of the base gasoline used for the blends.

3. Laboratory fuel blends of E55-E83 were produced by blending denatured ethanol with a single type of winter volatility gasoline. The flammability limits of these fuels showed a nonlinear relationship with both ethanol content and vapor pressure. Consequently, reducing the ethanol content of the fuels from typical E85 levels ( $80 \%$ or more) initially produced substantial reductions in the temperature at which it was possible for flammable vapors to form. Reductions in ethanol content below about $60 \%$ had a smaller relative impact on the flammability limits.

4. The laboratory fuel blends were produced from a "typical" winter volatility gasoline, with a dry vapor pressure equivalent (DVPE) value of $89 \mathrm{kPa}$. None of the blends produced from this gasoline could simultaneously meet the ASTM D5798 requirements for minimum vapor pressure $(66 \mathrm{kPa})$ and minimum ethanol content $(70 \%)$. The vapor pressure data for the blends indicated that a reduction in ethanol content to about $65 \%$ would be needed to achieve the minimum vapor pressure specification. The flammability data trends suggest that blends with ethanol content in this region would provide a favorable trade-off between avoiding the formation of flammable vapors and maximizing the ethanol content of the fuel.

5. Comparisons of the flammability results of the field and laboratory samples indicate that vapor pressure (DVPE) alone does not adequately predict the flammability of the fuel tank vapors formed at low temperatures. The properties of the hydrocarbon portion of the fuel must be considered as well.

6. It is recommended that further testing be carried out with laboratory fuels to examine the effects of gasoline volatility on the vapor flammability of the ethanol/gasoline blends. Flammability results over a wider range of ethanol content levels (including base gasoline without ethanol) are needed to elucidate the interactions between ethanol content, gasoline volatility, blend vapor pressure, and vapor flammability.

7. When some basic properties of the base oxygenate-free gasoline are known, then the mathematical model developed in this study can be used to compare the flammability characteristics of various gasoline-ethanol blends quite satisfactorily. The model requires ASTM D86 distillation data, D4052 specific gravity, and D5191 DVPE of the base oxygenate-free gasoline and the percentages of ethanol and gasoline in the blend.

8. The use of conventional flammability data leads to the prediction of higher rich limit temperatures than those actually measured in the experimental apparatus used in the study. Although an adjustment might be made to better match the predictions to the 
measurements, this is unlikely to be worthwhile, since it would again be apparatus dependent and not necessarily applicable to other conditions. Rather, the model is useful in comparing blends to each other to assess their relative hazards.

9. Since the project had sufficient gasoline data only for the laboratory blends tested for flammability, further work is needed to compare ethanol blends containing different gasoline base stock. This would allow an assessment to be made of the reliability of the model for comparing the relative hazards of different fuel sources.

10. Since most gasolines now contain some oxygenates, the distillation (D86) data for the base gasoline alone is often not available. Given the success of the model, it would be desirable to attempt to devise a technique for extracting the necessary gasoline data from the D86 data of a low alcohol blend. That is not trivial, but comparisons such those made of the special E0 and E10 fuels studied in this project may allow such a technique to be developed, thereby making the model much more accessible for use by others. 


\section{Table of Contents}

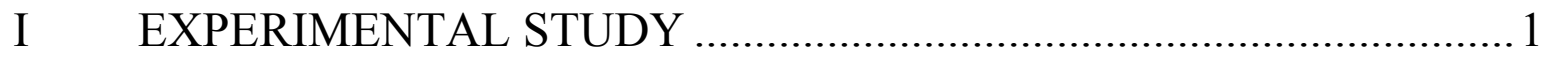

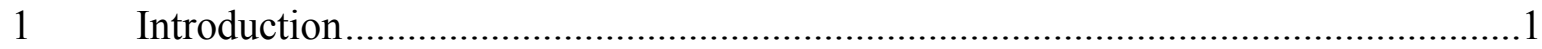

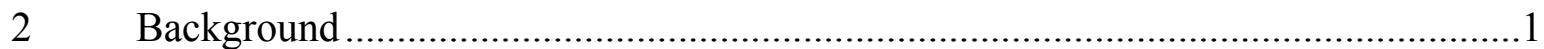

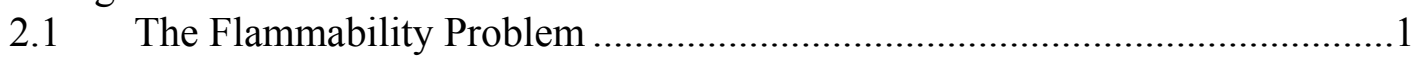

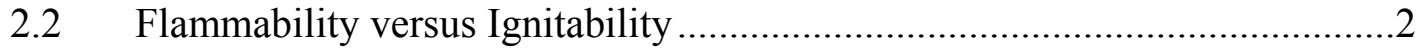

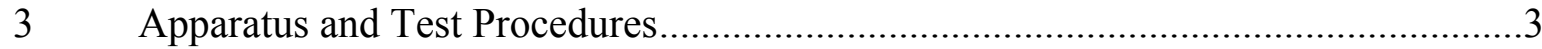

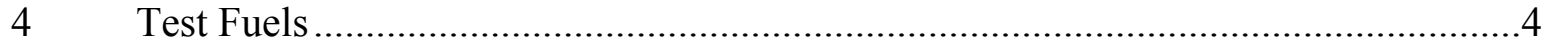

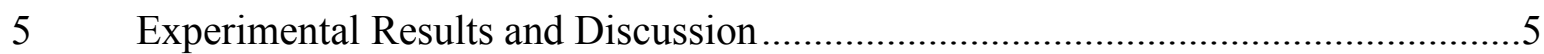

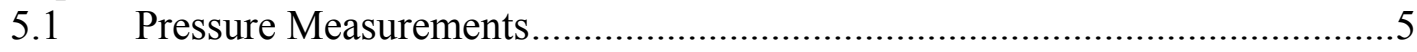

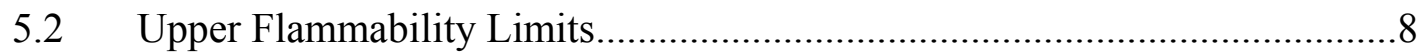

$6 \quad$ Conclusions from Experimental Study ................................................................11

II MATHEMATICAL MODELING STUDY ....................................... 13

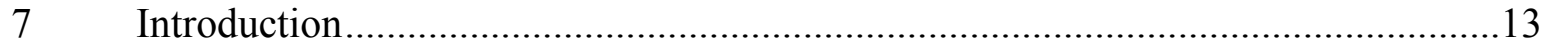

$8 \quad$ Scope of the Present Modeling Study .................................................................14

$9 \quad$ Validation Using the Specific Tests and Test Fuels ..............................................15

$10 \quad$ Modeling the Laboratory Blends ........................................................................18

11 Comparison of Predicted and Measured Flammability of Fuel Tank

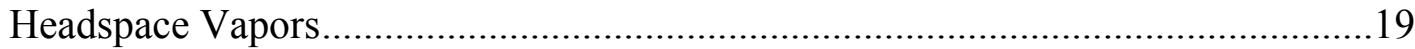

12 Conclusions from the Modeling Study ..............................................................21

III OVERALL CONCLUSIONS AND RECOMMENDATIONS ............22

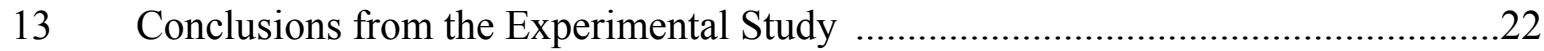

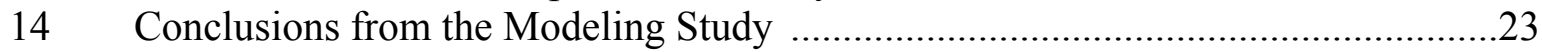

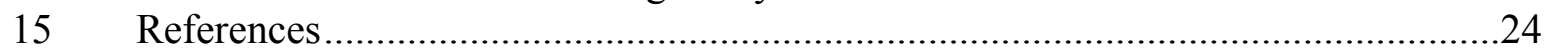

APPENDIX A: Properties of Field Samples ….......................................26

APPENDIX B: Properties of Laboratory Samples .................................2

APPENDIX C: Summary of the Models for the Volatility and Flammability

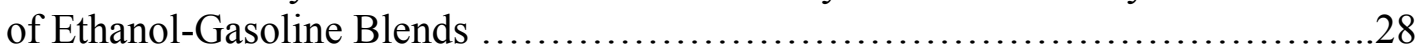

APPENDIX D: Alberta Research Council-Fuels \& Lubricants

Report of Analysis ........................................................ 31 


\section{List of Figures}

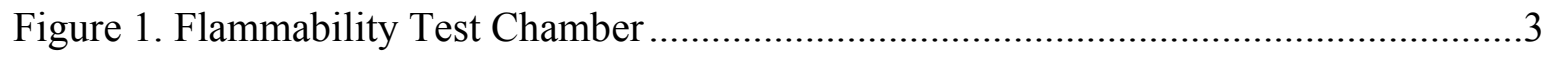

Figure 2. Maximum Pressure Rise of Field Fuel Samples.....................................................5

Figure 3. Maximum Rate of Pressure Rise of Field Fuel Samples ...........................................6

Figure 4. Maximum Pressure Rise of Laboratory Fuel Samples .............................................7

Figure 5. Maximum Rate of Pressure Rise of Laboratory Fuel Samples ...............................8

Figure 6. Effect of Ethanol Content on Upper Flammability Limit ......................................9

Figure 7. Effect of Ethanol Content on Vapor Pressure (DVPE) of Test Fuels ....................10

Figure 8. Effect of Vapor Pressure (DVPE) on Upper Flammability Limit of Test Fuels ...11

Figure 9. Measured and Predicted Vapor Pressures - Indolene @ $0^{\circ} \mathrm{C}$................................14

Figure 10. Measured and Predicted Vapor Pressure of ARC Gasoline (V/L=4) .................17

Figure 11. Measured and Predicted Vapor Pressure of ARC E10 Blend $(\mathrm{V} / \mathrm{L}=4)$...............17

Figure 12. Measured and Predicted DVPE of Laboratory Samples ......................................19

Figure 13. Measured and Predicted Flammability of Tank Headspace Vapors ....................20 


\section{EXPERIMENTAL STUDY}

\section{Introduction}

The project described in this report was carried out to examine the potential for flammable fuel/air mixtures to form in fuel tanks containing blends of ethanol and gasoline. The current project followed an earlier project [1] in which an experimental technique and a mathematical model were developed to investigate the flammability issue. The ethanol/gasoline blends evaluated in the first project were experimental fuels originally produced for vehicle drivability studies. These blends (referred to as E85 fuels) contained about 70-80\% ethanol and a variety of hydrocarbon components.

In the current project, two sets of fuels were investigated. The first set consisted of "real world" fuel samples obtained from refuelling stations, which are referred to as "field samples"

throughout this report. These samples included E85 blends, as well as low- and mid-level blends containing approximately $10-30 \%$ ethanol. Investigations involving these fuels were intended to provide information about the possibility of flammable mixtures forming with the fuels that are currently available.

The second set of fuels (provided by Marathon Petroleum Company) was produced in a laboratory to systematically investigate the effects of varying ethanol content on the volatility and flammability of the resulting blends. These fuels were produced by blending denatured ethanol with varying percentages a single type of gasoline. The gasoline used for the blends had properties that were representative of a typical winter grade fuel. Investigations involving these fuels were intended to provide information to guide future fuel specifications. Such specifications could be developed based upon knowledge of the compromise between avoiding flammable mixtures at low ambient temperatures and maximizing the ethanol content of the fuel.

\section{$2 \quad$ Background}

\subsection{The Flammability Problem}

Gasoline is so volatile at most ambient temperatures that the headspace vapors (the gaseous fuel/air mixture above the liquid in the fuel tank) are actually too rich to burn, as long as some liquid fuel remains. However, as temperature drops, or as the liquid fuel level goes down, the volatility of the fuel decreases. As the liquid level drops, there is less fuel vapor mixed with the air in the tank.

If the ambient temperature is cold enough and the tank is nearly empty, then the fuel-air mixture in the tank becomes flammable and can pose an explosion hazard if ignited. This has always been the case with gasoline, but the temperatures and fill levels needed to produce a hazard are rarely encountered, so fires and tank explosions are very unlikely, although not impossible.

Ethanol by itself in a fuel tank produces headspace vapors that are flammable at room temperature and over a broad range of commonly encountered ambient temperatures. Ethanol/gasoline blends generally have volatility characteristics between those of the two major 
constituents. Any given high-alcohol blend tends to produce flammable fuel tank vapors at higher (i.e., less cold) temperatures than pure gasoline. The extent of the difference, and hence of any increased risk, depends on composition of the gasoline part of the blend and how much gasoline is present in the fuel mixture [2-5]. It is therefore prudent to assess the extent of any differences in the fire hazards of fuel tank headspace vapors between gasoline and ethanol fuel blends.

The standard specifications for fuel ethanol are described in ASTM D5798 [6], which provides three different vapor pressure classes for fuel ethanol, depending upon the seasonal and climatic conditions that apply. The coldest of these is referred to as Class 3, which encompasses geographic areas with 6-h tenth percentile minimum ambient temperature less than or equal to $-5^{\circ} \mathrm{C}$. Since low ambient temperatures present the greatest risk of the formation of flammable headspace vapors, Class 3 fuels and climatic conditions are the focus of the current study.

\subsection{Flammability versus Ignitability}

A fuel-air mixture is considered to be flammable if, when ignited, it produces a flame that can propagate throughout the available mixture. A flammable mixture might fail to ignite if the ignition source is too weak. However, successful ignition does not guarantee successful flame propagation. In some cases, the ignition source is strong enough to initiate a small flame, but the flame is extinguished as it moves away from the ignition source. In such cases, only a portion of the available mixture is burned, and the mixture is not, therefore, considered flammable.

In the present study, the objective was to determine the flammability of the headspace vapors from different fuels. As such, the strategy was to employ an ignition source strong enough to ensure that any flammable mixture could be ignited reliably. With this achieved, flammability experiments should show evidence of partial combustion when the limits are reached.

The use of closed combustion chambers and pressure measurements in the experiments provided a means of differentiating between ignition failures, successful ignition followed by partial flame propagation, and substantially complete flame propagation. Tests in which the mixture fails to ignite show no increase in chamber pressure. Partial flame propagation produces a small but detectable pressure rise.

Tests in which most of the mixture in the chamber is burned should exhibit similar peak pressure levels. Assuming nearly complete flame propagation, differences in peak pressure levels would mainly be due to differing amounts of heat lost to the chamber walls. As the flammability limits are approached, greater heat losses (therefore, lower peak pressure levels) are expected due to slower combustion. However, even these reduced pressure levels are well above those that occur when only a small portion of the mixture is burned (i.e., the partial propagation case).

Another diagnostic tool for examining flame propagation in the chamber is the rate of pressure rise. The rate of pressure rise (obtained through differentiation of the pressure signal) reflects the overall heat release rate within the chamber. This rate is influenced by the laminar burning velocity of the mixture and the surface area of the flame front. For example, a weak flame that extinguishes near the ignition source will reach a relatively small maximum surface area and will have a relatively low burning velocity prior to extinction. These factors will result in a very low rate of pressure rise compared with a case in which combustion is nearly complete. The rate of 
pressure rise also provides a sensitive means of comparing cases with similar peak pressure levels but different combustion rates. The peak rate of pressure rise falls as the flammability limit is approached.

\section{$3 \quad$ Apparatus and Test Procedures}

Eight identical test chambers were constructed so that a number of fuel samples could be chilled simultaneously. Photographs of one of the test chambers are shown in Figure 1. The interior volume of each chamber was $296 \mathrm{~mL}$.
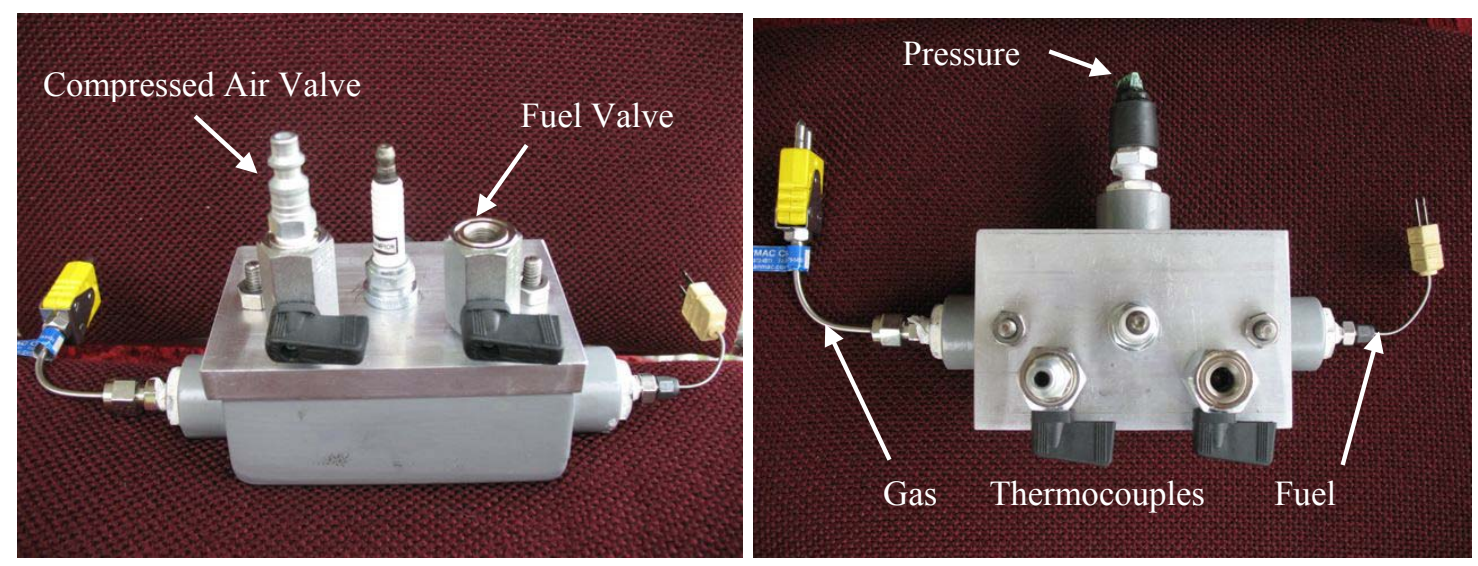

Figure 1. Flammability Test Chamber

The pressure sensor was a Honeywell model 19CP300PA4K absolute pressure sensor with a fullscale range of $0-2,070 \mathrm{kPa}(0-300 \mathrm{psia})$. The sensor had a response time of $0.1 \mathrm{~ms}$, which was found to be fast enough to capture the transient features of the pressure rise events during combustion. The gas temperature inside the chamber was measured using a Nanmac "right angle" K-type thermocouple. This thermocouple was a fast-response design with a low-inertia ribbon junction. The thermocouple was not fast enough to detect the actual transient gas temperature during combustion, but it could track the dynamic temperature behavior well enough to provide relative comparisons between tests.

The temperature of the liquid fuel at the bottom of the chamber was measured using a conventional 1.6-mm (1/16 in.) sheathed K-type thermocouple with a grounded junction. This thermocouple was positioned so that it would be immersed in the liquid layer (about $5 \mathrm{~mm}$ deep).

The ignition source for the experiments was composed of an automotive spark plug and a laboratory programmable ignition system. The ignition system discharged $1 \mathrm{~J}$ of stored energy during each spark, producing a saw-tooth spark current waveform (50-100 mA) with a duration of $1 \mathrm{~ms}$. The spark plug was a Champion model 7034, which had platinum pins in the center and ground electrodes. This type of spark plug was selected because the pins ensure that the spark location is consistent from spark to spark. The electrode gap was set at $2 \mathrm{~mm}$ (0.079 in). This particular spark plug model also had a projected tip, which placed the spark gap closer to the vertical center of the chamber. 
The experiments were carried out in an Espec model PUA-3AP temperature chamber. During most of the experiments, all eight fuel chambers were chilled together. The fuel chambers were placed on racks within the "assured test volume" of the temperature chamber, where (according to the manufacturer) the rated temperature uniformity $\left( \pm 0.5^{\circ} \mathrm{C}\right)$ should exist. During some tests, the same type of fuel was used in each chamber. In other cases, two or three different fuels were tested. The choice of fuel for the chambers depended on the test temperature and the results of previous tests.

All the experiments were conducted using a $1 / 20^{\text {th }}$ (5\%) fill level. As shown by Vaivads et al. [3], the fuel tank headspace vapors of gasoline and alcohol/gasoline blends are flammable at higher temperatures if there is less liquid fuel in the tanks. The 5\% fill level was selected, in consultation with the project sponsor, to represent a worst-case scenario in terms of how low an automobile operator might allow the fuel level to become.

The fuel storage containers and the syringes used to transfer the fuel were stored at $-12^{\circ} \mathrm{C}$. Before each test, fuel was extracted with a syringe from one of the fuel storage containers and transferred to the appropriate test chamber. The storage container was opened just long enough to extract the fuel (to limit vapor losses from the samples), and the test chamber was sealed immediately after the fuel was injected through the fuel valve.

The sealed chambers were placed in the cold chamber, connected to the instrumentation cables, and chilled until the gas temperature inside the chamber reached the desired test temperature. This initially caused the gas pressure in the chambers to fall below atmospheric pressure. The chamber pressure levels were then equalized to atmospheric pressure by quickly opening and closing each fuel valve. Following equalization, the chambers were cold soaked until the gas and fuel temperatures were within $0.5^{\circ} \mathrm{C}$ of each other and then maintained at the test temperature $\left( \pm 0.5^{\circ} \mathrm{C}\right)$ for at least 1 hour before ignition was attempted.

During each ignition attempt, the data acquisition system was activated and the ignition system was triggered. The ignition system sparked at a frequency of $2 \mathrm{~Hz}$ once triggered. Flammable mixtures usually ignited with the first spark.

\section{$4 \quad$ Test Fuels}

Two different sets of fuels were tested. The first group of fuels were field samples obtained at two different refueling facilities. These facilities were equipped with storage tanks for gasoline and E85, and "blender pumps" that could create intermediate ethanol/gasoline blends for the "parent" gasoline and E85. The second set of fuels was produced in a laboratory by blending a well-characterized gasoline sample (intended to represent typical winter gasoline properties) with varying percentages of denatured ethanol. The properties of the test fuels are listed in Appendix A. 


\section{$5 \quad$ Experimental Results and Discussion}

\subsection{Pressure Measurements}

Rapid City, SD, and Lucerne, MN, blender pump field samples: Figures 2 and 3 show the test chamber pressure measurements for the fuel samples obtained from the Rapid City, SD, blender pump location and an E85 sample from Lucerne, MN. The E20 SD and E30 SD samples were created by the blender pump by combining the gasoline (E10 SD) and E85 SD available at that location. All of these fuels had relatively low vapor pressure values considering that the samples were collected during a season when ASTM Class 3 fuels should have been provided. The DVPE values of the E85 SD and E85 MN samples were only $38.4 \mathrm{kPa}$ and $42.4 \mathrm{kPa}$, respectively - well below the ASTM D5798 Class 3 minimum value of $66 \mathrm{kPa}$. The E10, E20, and E30 samples had DVPE values of $60.8 \mathrm{kPa}, 59.2 \mathrm{kPa}$, and $58.2 \mathrm{kPa}$, respectively.

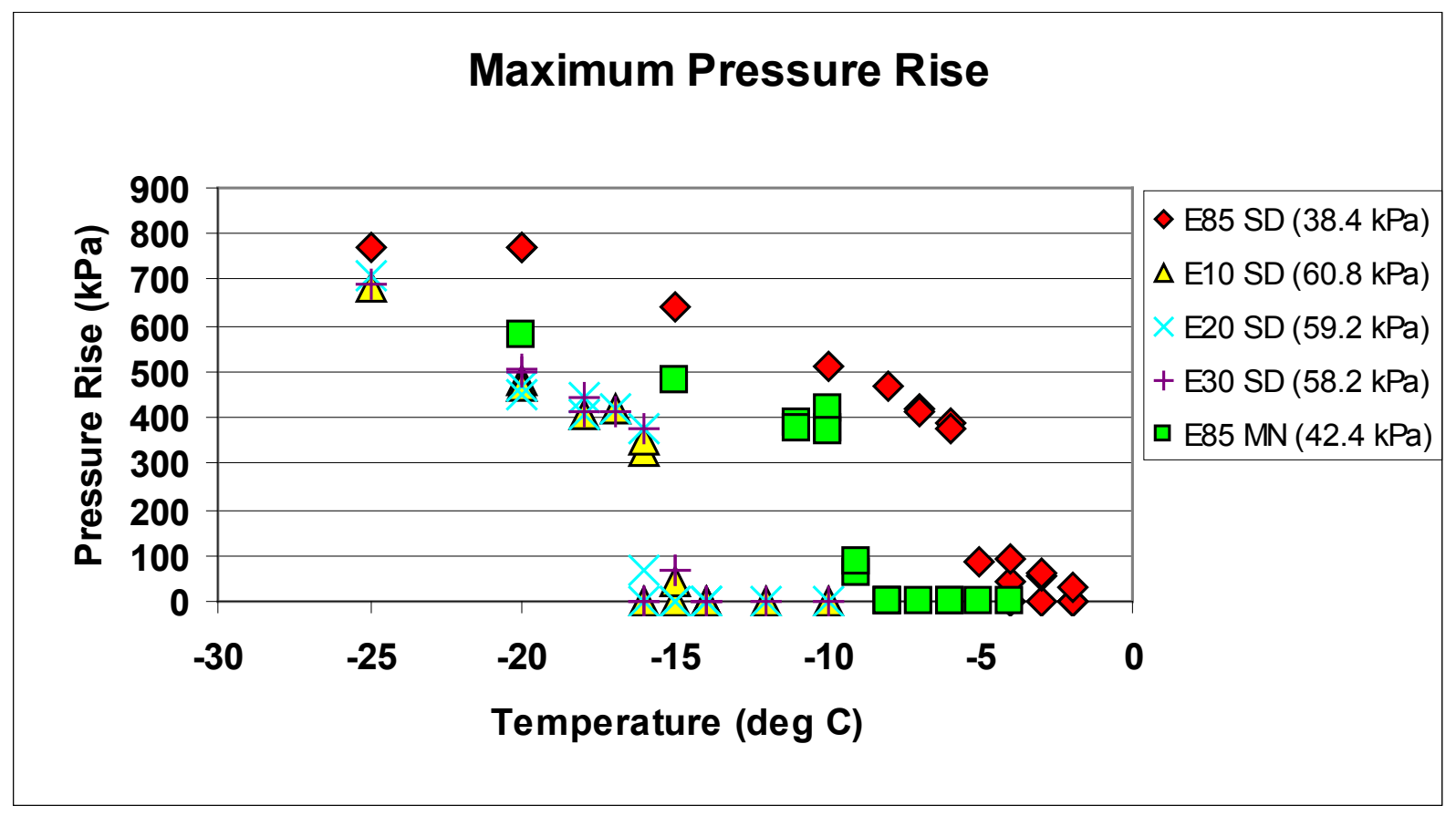

Figure 2. Maximum Pressure Rise of Field Fuel Samples 


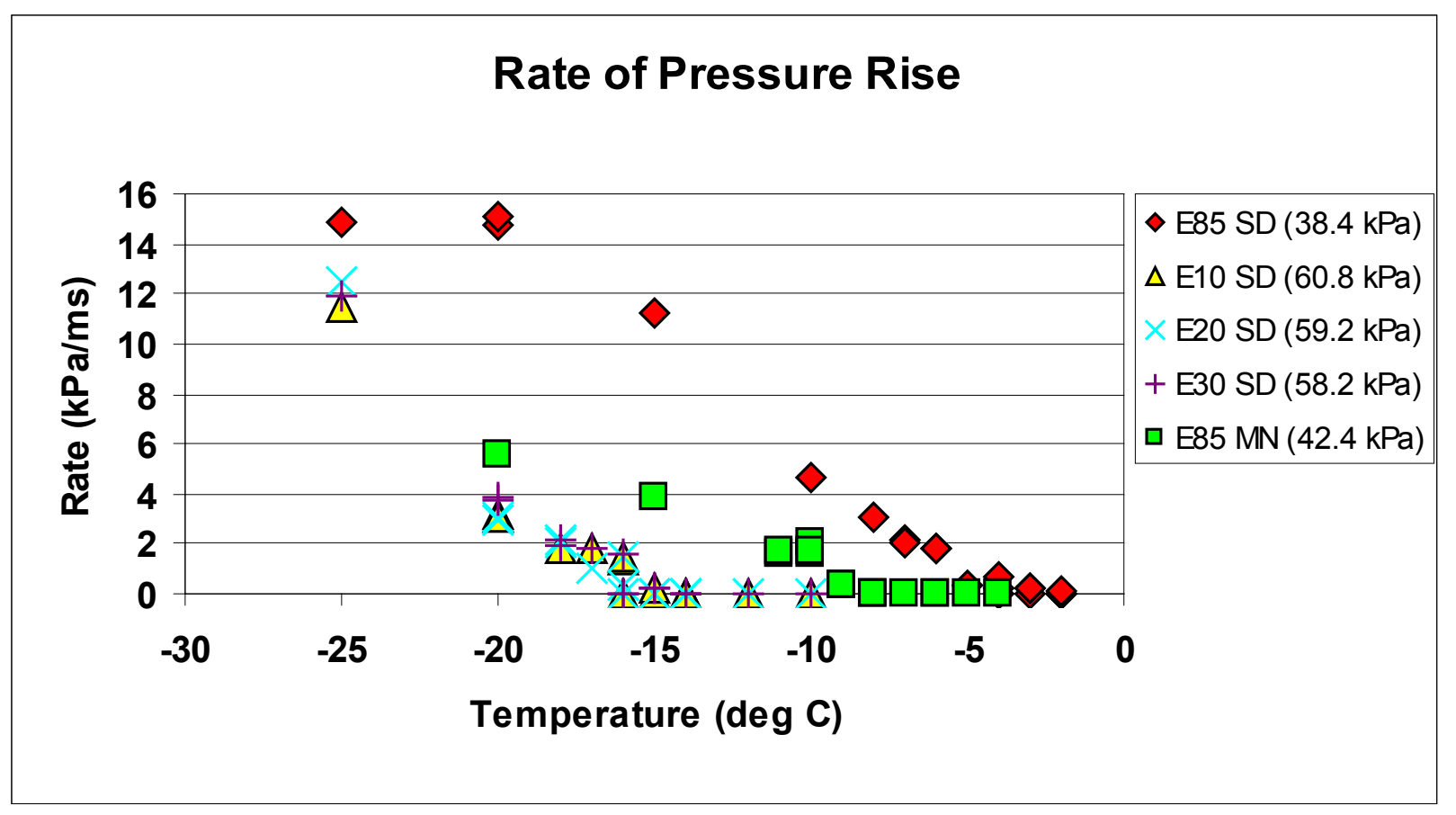

Figure 3. Maximum Rate of Pressure Rise of Field Fuel Samples

As shown in Figure 2, the pressure rise values were either below $100 \mathrm{kPa}$ or above $300 \mathrm{kPa}$. Similar behavior was also seen in the previous study [1]. The tests where only a low pressure rise was produced are believed to indicate cases where the mixture could be ignited by the apparatus, but only a small portion of the mixture in the chamber was burned. Test results in the higher pressure range indicate that a substantial portion of the mixture in the chamber was burned, so the mixture was, by definition, flammable.

Since each fuel tested produced some low pressure results, it is proposed that the spark ignition source was strong enough to ensure that the apparatus was capable of identifying true flammability limits rather than ignition limits imposed by the ignition source. In other words, the spark energy of this apparatus was great enough to ensure that it could ignite any mixture that was capable of sustained burning once it was ignited. For all of the fuels tested, only upper flammability limits were encountered. That is, the vapor/air mixture in the chamber headspace was flammable below a critical temperature and was too rich to burn above that temperature.

The results for the maximum rate of pressure rise shown in Figure 3 provide a relative indication of how fast the mixture burned following ignition. This is related to the flame speed of the mixture, and affects both the potential destructiveness of combustion within a fuel tank and the potential for igniting the mixture with relatively weak sparks. A well-known example of this relationship is hydrogen, which is easily ignited and potentially destructive because it has a high flame speed.

As shown in Figure 2, the maximum pressure rise results for the E10-E30 samples were almost identical. The maximum rate of pressure rise at any given temperature (Figure 3) also varied 
little between the E10-E30 samples. Thus, blending E85 with the base E10 gasoline up to E30 levels had little or no effect on the combustion properties of the fuel.

The E85 field samples were ignitable and flammable at substantially higher temperatures than the low-medium level ethanol blends. The E85 SD sample was particularly noteworthy, as it produced much higher maximum pressure rise rates over the temperature range typical of Class 3 climatic regions. For example, all of the fuel samples were flammable at $-20^{\circ} \mathrm{C}$, but the maximum rate of pressure rise was nearly 4 times higher with the E85 SD fuel.

An even greater difference would be expected if the E85 fieled samples were compared with more volatile winter gasoline, such as the "typical" winter gasoline used to produce the laboratory blends for this project ( $89.2 \mathrm{kPa}$ DVPE). As previously noted, the E10 gasoline sample (at $60.8 \mathrm{kPa}$ DVPE) had an unusually low vapor pressure for a winter fuel

Laboratory ethanol/gasoline blends: The pressure rise and rate of pressure rise results for the blends of denatured ethanol and winter grade gasoline are shown in Figures 4 and 5. Like the field samples discussed earlier, these fuels produced pressure rise results that were bimodal in nature ( $<100 \mathrm{kPa}$ or $>300 \mathrm{kPa})$, indicating that the ability to achieve results in the high pressure range was not limited by the ignition source. The ranking of the fuel blends was as expected, but it can be seen that there were only small differences between E60 and E55 in terms of the pressure rise and rate of pressure rise results.

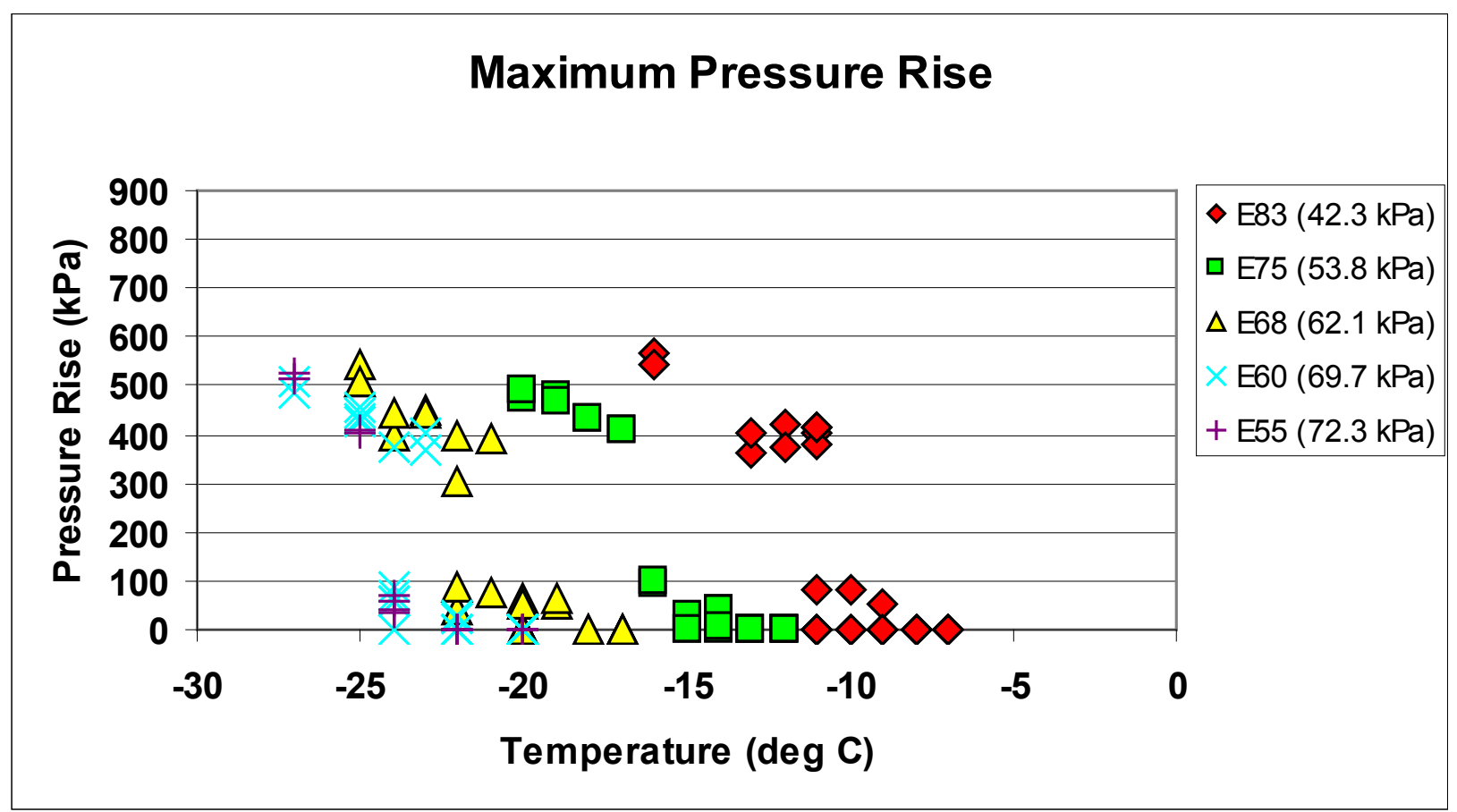

Figure 4. Maximum Pressure Rise of Laboratory Fuel Samples 


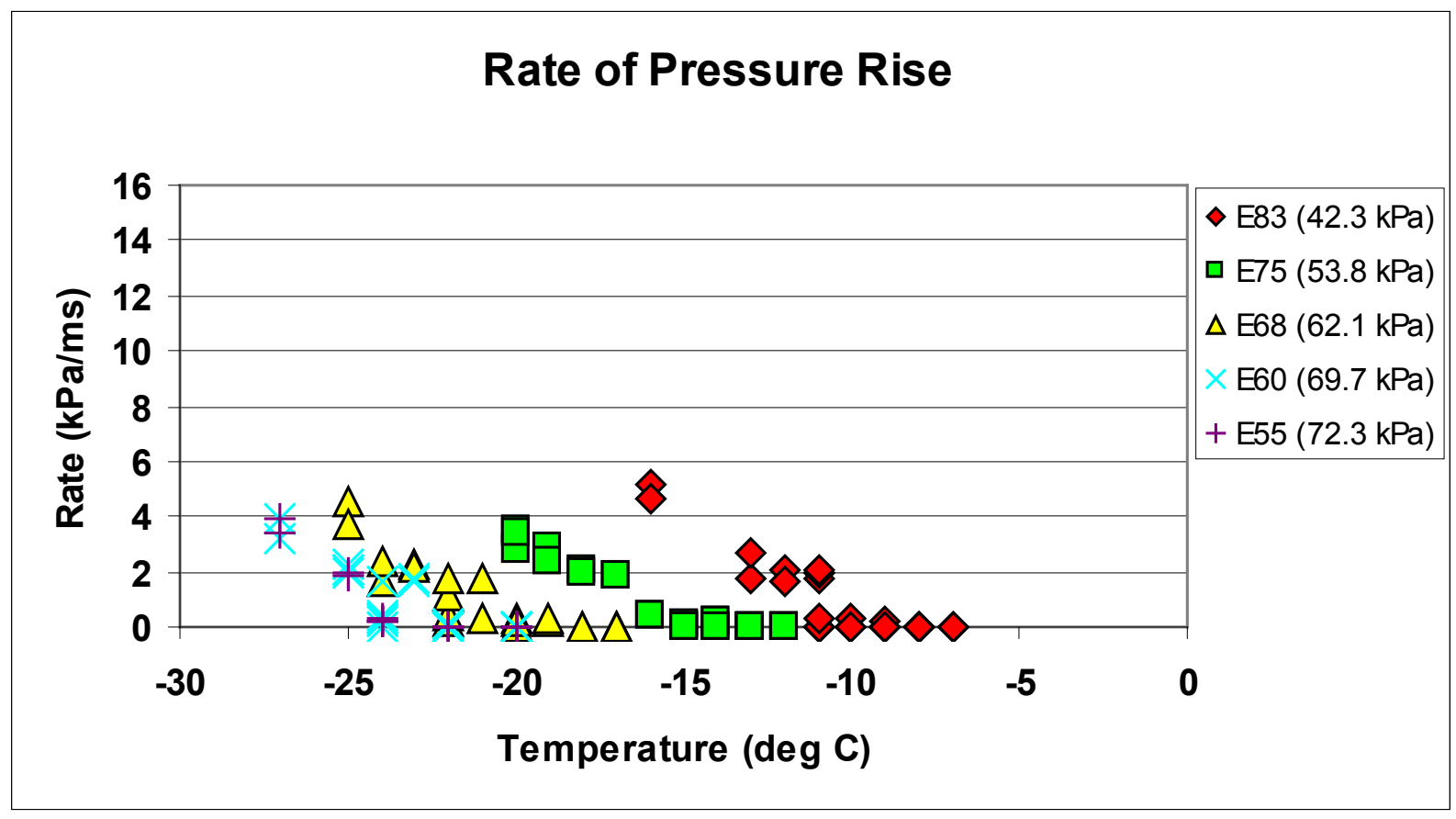

Figure 5. Maximum Rate of Pressure Rise of Laboratory Fuel Samples

\subsection{Upper Flammability Limits}

Based upon the pressure rise data shown in Figures 2 and 4, a statistical analysis was carried out to arrive at values for the upper flammability limits of each fuel and their associated uncertainties. Statistical analysis of the peak pressure rise data was implemented using a PROBIT technique [7]. The use of this digital technique was justified by the binomial nature of the data. A threshold pressure of $200 \mathrm{kPa}$ was used to differentiate between flammable mixtures that were ignitable but not flammable.

In the analysis, pressure rise values in the high-pressure range (representing flammable mixtures) were assigned a high logic value (1), while pressure rise values in the low-pressure range (ignitable but not flammable) and zero pressure rise values (ignition failure) were assigned a low logic value (0). The technique generated a most likely curve fit for the temperature region where both high-pressure and low-pressure results were recorded in the experiments. From this curve fit, the mean temperature value and the upper bound temperature value were determined. The criterion chosen for the upper bound temperature was a $50 \%$ probability (at $95 \%$ confidence) of a high-pressure event occurring.

In the following flammability limit graphs, the mean values have been plotted. The error bars are based upon the accuracy of the temperature measurements (conservatively estimated to be within $\pm 1^{\circ} \mathrm{C}$ ), with difference between the upper bound and the mean value added to the plus side of the error bar. Thus, the upper error limits represent the highest temperature at which there would still be at least a $50 \%$ probability that the mixture was flammable.

In Figure 6, the upper flammability limits of the field samples and the laboratory fuels are plotted versus their respective ethanol content (volume $\%$ as determined by analysis). Note that since 
these are upper (rich) flammability limits, the fuel/air vapors are flammable at or below the temperatures show. The E85 SD field sample was flammable at temperatures up to $-5^{\circ} \mathrm{C}$ and was therefore flammable over the entire ASTM Class 3 temperature range. The flammability limits of the E85 MN field sample and the E83 laboratory blend were somewhat lower, at about $-10^{\circ} \mathrm{C}$ and $-11^{\circ} \mathrm{C}$, respectively.

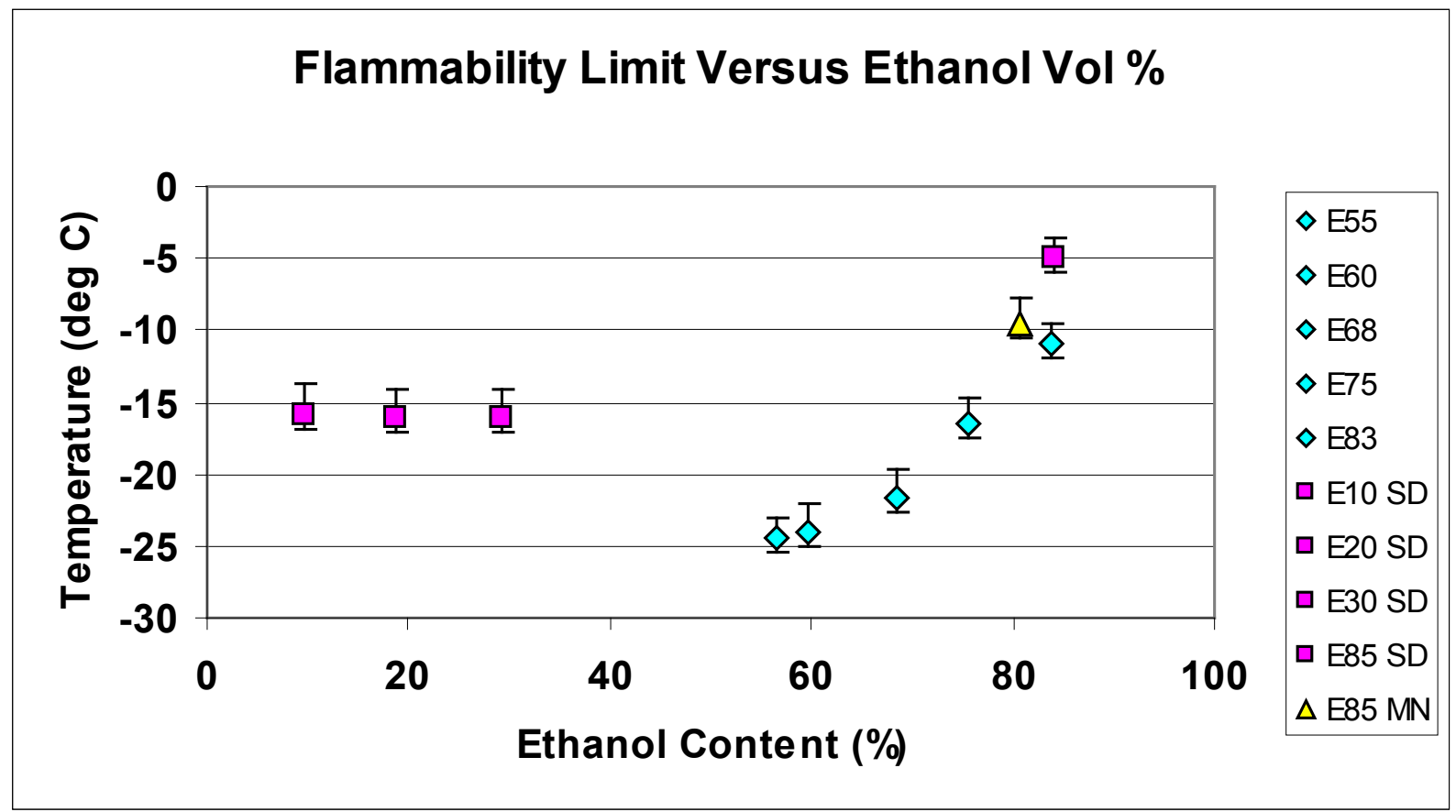

Figure 6. Effect of Ethanol Content on Upper Flammability Limit

There was no significant difference in the flammability limits of the E10 SD-E30 SD field samples. These results suggest that the E20 and E30 fuels produced by existing blender pumps (from E10 and E85 "parent" fuels) may not pose an increased flammability risk relative to their E10 component. As such, they offer a means of increasing the utilization of ethanol without the flammability risks inherent in the use of high-level blends such as E85.

The results for the laboratory fuel blends show a nonlinear relationship between the ethanol content of the fuel and its upper flammability limit. As such, reducing the ethanol content from typical E85 levels initially provides a substantial reduction in the temperature at which flammable mixtures are likely to form. Reductions below about $60 \%$ ethanol appear to have a more modest effect.

Figure 7 shows the measured DVPE values of the test fuels as a function of ethanol content. The vapor pressure of the ethanol-free base gasoline used to produce the laboratory blends is also shown. The minimum values for ethanol content and vapor pressure for Class 3 fuels (specified in ASTM D 5798-09) are depicted for comparison. Based upon the curve fit for the laboratory fuels, it appears that the ethanol content of fuels blended with this particular base gasoline would have to be reduced to about $65 \%$ (below the recommended minimum of $70 \%$ ) to achieve the Class 3 minimum DVPE value of $66 \mathrm{kPa}$. 


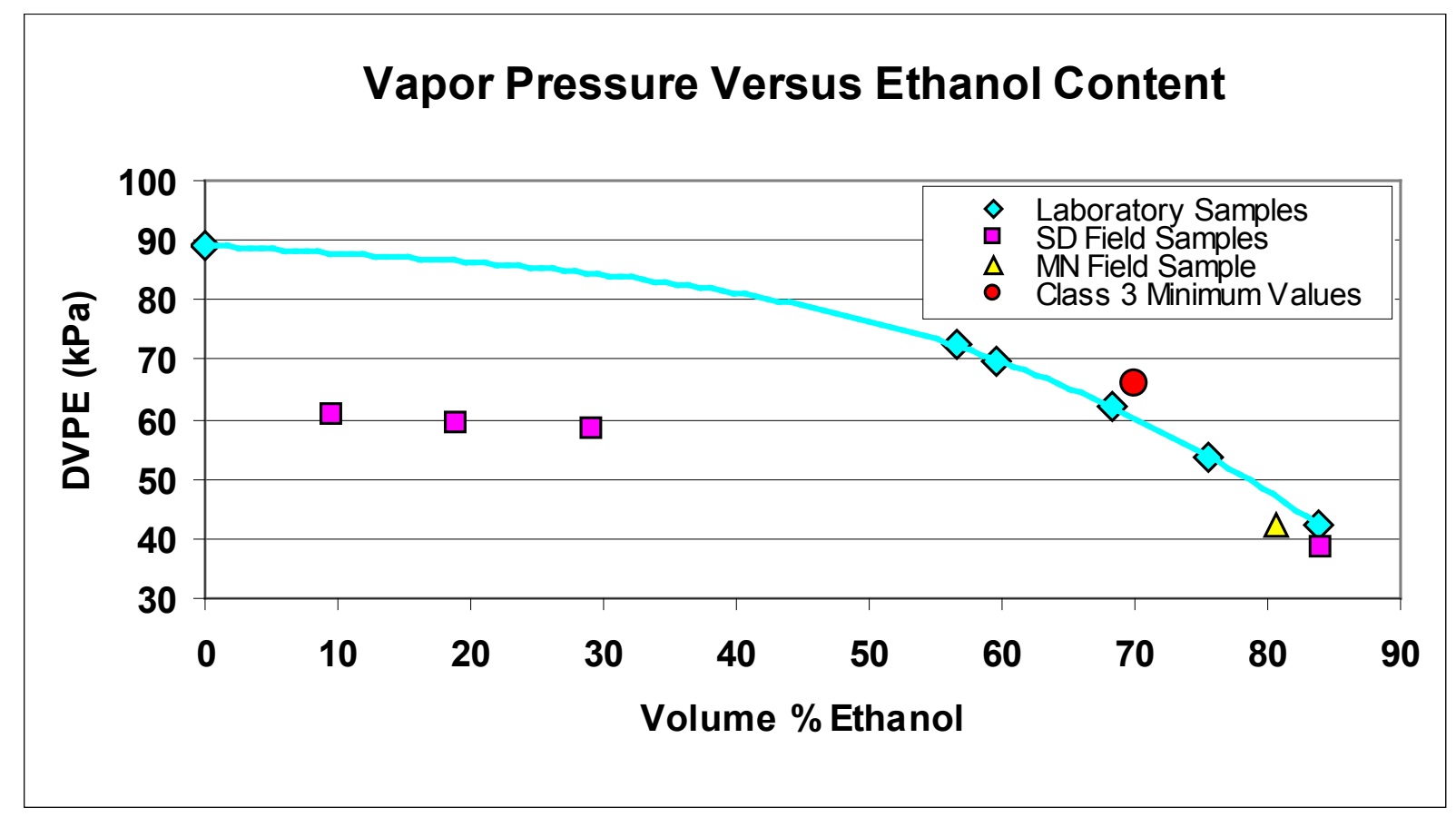

Figure 7. Effect of Ethanol Content on Vapor Pressure (DVPE) of Test Fuels

It also appears that the E10-E30 field samples had lower DVPE values than similar blends with this base gasoline would be expected to have. This suggests that the gasoline portion of the E10E30 field samples was less volatile than the "typical" winter gasoline used to produce the laboratory blends. On the other hand, the E85 field samples and the E83 laboratory fuel had similar vapor pressure values. The E83 and the E85 MN samples had DVPE values of $42.3 \mathrm{kPa}$ and $42.4 \mathrm{kPa}$, respectively, while the E85 SD sample was slightly lower, at $38.4 \mathrm{kPa}$.

Figure 8 shows the upper flammability limits of the fuels as a function of their respective vapor pressure values. The data from the laboratory fuels indicates that the relationship between the flammability limit and the vapor pressure of the fuels is nonlinear. The impact of increasing vapor pressure (achieved by decreasing ethanol content) was diminished when the percentage of ethanol was lower. The fact that the E10-E30 field samples had the same flammability limit temperature (within the resolution of the experiments), despite significant differences in their vapor pressure values, is consistent with this observation for the laboratory samples. Further experiments with laboratory samples in the E0-E55 range are needed to confirm this apparent trend. 


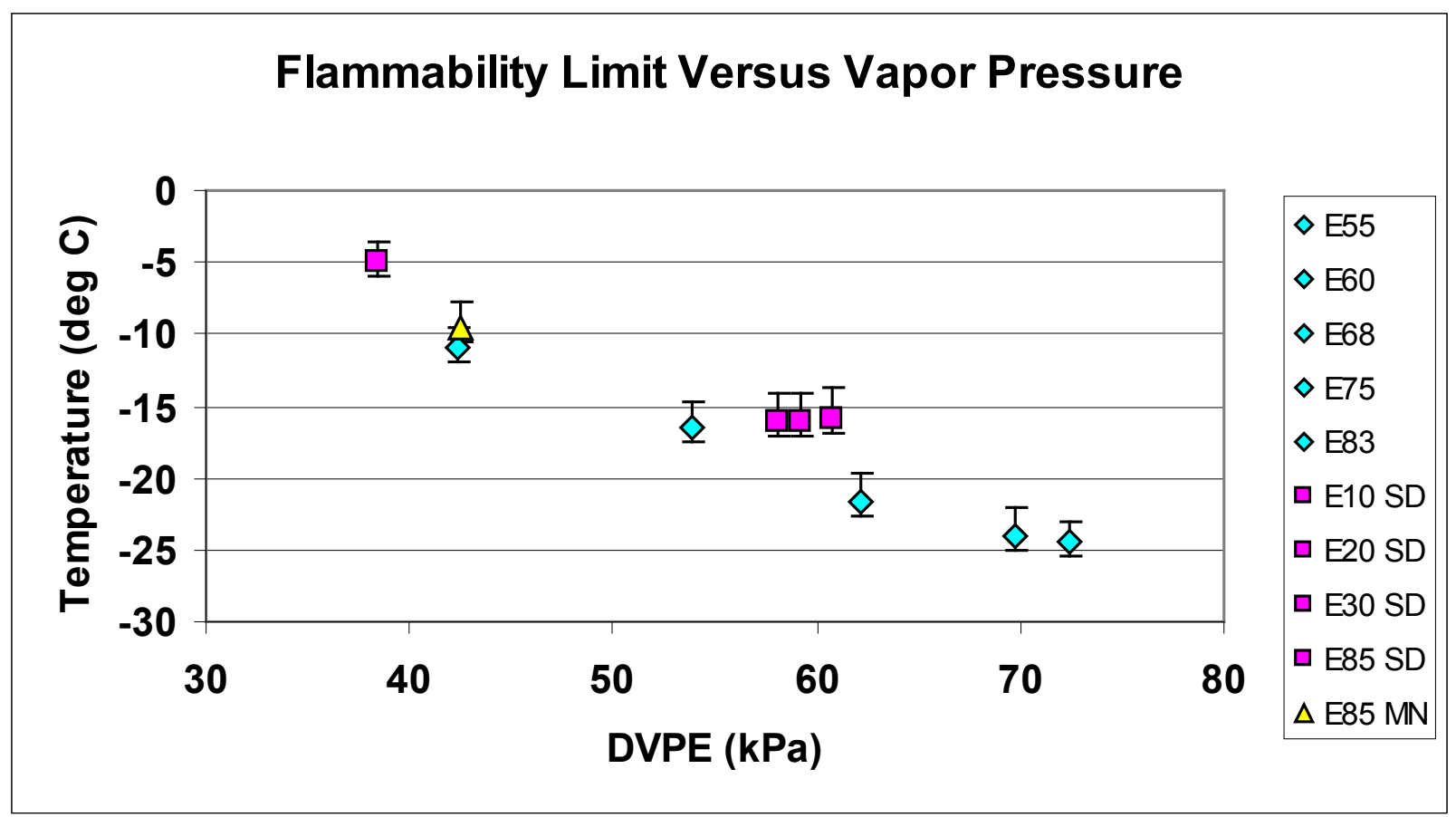

Figure 8. Effect of Vapor Pressure (DVPE) on Upper Flammability Limit of Test Fuels

Note that at similar vapor pressure levels, the flammability limits of the laboratory blends were significantly lower than those of the E10-E30 blends. This is consistent with earlier observations that the vapor pressure (DVPE value) alone does not adequately predict the flammability of the fuel tank vapors formed at low temperatures [1]. Evidently, the properties of the hydrocarbon portion of the fuel must be considered as well.

\section{$6 \quad$ Conclusions from Experimental Study}

1. Both of the E85 field samples that were tested had vapor pressure values well below the minimum Class 3 specifications of ASTM D5798-09. One of these fuels produced flammable vapors over the entire Class 3 temperature range $\left(-5^{\circ} \mathrm{C}\right.$ and below). The other fuel produced flammable vapors at $-10^{\circ} \mathrm{C}$ and below. These results indicate that at least some of the ethanol fuels that are currently available when and where Class 3 conditions exist are likely to produce flammable vapors within the ambient temperature range where they are used.

2. Two mid-level ethanol blends (E20 and E30) were tested. These field samples were produced by a blender pump that mixed E10 (the base gasoline available at that location) with E85. No significant differences could be measured between vapor flammability limits of the E20-E30 samples and the E10 sample they were produced from. These results indicate that mid-level blends in this range are unlikely to significantly increase the risk of producing flammable vapors over that of the base gasoline used for the blends. 
3. Laboratory fuel blends of E55-E83 were produced by blending denatured ethanol with a single type of winter volatility gasoline. The flammability limits of these fuels showed a nonlinear relationship with both ethanol content and vapor pressure. Consequently, reducing the ethanol content of the fuels from typical E85 levels (80\% or more) initially produced substantial reductions in the temperature at which it was possible for flammable vapors to form. Reductions in ethanol content below about $60 \%$ had a smaller relative impact on the flammability limits.

4. The laboratory fuel blends were produced from a "typical" winter volatility gasoline, with a DVPE value of $89 \mathrm{kPa}$. None of the blends produced from this gasoline could simultaneously meet the ASTM D5798 requirements for minimum vapor pressure (66 $\mathrm{kPa})$ and minimum ethanol content $(70 \%)$. The vapor pressure data for the blends indicated that a reduction in ethanol content to about $65 \%$ would be needed to achieve the minimum vapor pressure specification. The flammability data trends suggest that blends with ethanol content in this region would provide a favorable trade-off between avoiding the formation of flammable vapors and maximizing the ethanol content of the fuel.

5. Comparisons of the flammability results of the field and laboratory samples indicate that vapor pressure (DVPE) alone does not adequately predict the flammability of the fuel tank vapors formed at low temperatures. The properties of the hydrocarbon portion of the fuel must be considered as well.

6. It is recommended that further testing be carried out with laboratory fuels to examine the effects of gasoline volatility on the vapor flammability of the ethanol/gasoline blends. Flammability results over a wider range of ethanol content levels (including base gasoline without ethanol) are needed to elucidate the interactions between ethanol content, gasoline volatility, blend vapor pressure, and vapor flammability. 


\section{MATHEMATICAL MODELING STUDY}

\section{Introduction}

It is desirable to have a manageable mathematical model to characterize the volatility and flammability of ethanol gasoline blends. Such a model would permit the assessment of fuels with regard to flammability without resorting to costly and time-consuming combustion tests for every candidate fuel.

In Phase One of this work, it was shown that ethanol-gasoline blends could be represented using a modeling technique developed originally for methanol blends. The ethanol is treated using conventional methods for pure compounds. Its vapor pressure and vapor phase molecular weight are functions of temperature only and do not depend upon how much of the alcohol is evaporated. Gasoline, on other hand, is a multi-component mixture; its vapor pressure and vapor phase molecular weight depend on both the temperature and the extent of evaporation. When most of the fuel is liquid, the vapor pressure is high, but as evaporation occurs the vapor pressure drops by an order of magnitude, and the molecular weight of the vapor phase increases by a factor of 2-3.

The model being used for this work essentially treats a blend of alcohol and gasoline as a pseudo-binary mixture. The gasoline is modeled using a technique that allows both temperature and the extent of evaporation to be accounted for in determining vapor pressure and other proprieties. The ethanol is treated as a pure compound.

Details of the gasoline model, and the pseudo binary treatment of ethanol-gasoline blends were given in the report of Phase 1 [1] and are summarized in Appendix C.

Due to the limited nature of that initial study, and the data available on hydrocarbon components used in the various blends tested, it was not possible to create models of the hydrocarbon components in each blend in accordance with the full modeling technique. Instead, a number of existing models for representative gasoline primers were used. Those existing models covered representative low, medium and high volatility gasolines, Indolene and light iso-crackate (LIC), whose modeling coefficients were known from earlier work.

\section{Two important conclusions were drawn from the modelling results of Phase 1:}

1. Volatility at high temperatures such as that used in determining DVPE does not necessarily reflect the behaviour of the different ethanol blends at low temperatures. A simple comparison of DVPE as an indicator of low temperature flammability is insufficient and can be misleading.

2. Simply using generic gasoline models is not adequate to reliably assess low temperature flammability of a particular fuel blend. Details of the actual gasoline properties used to make the blend are required. 


\section{$8 \quad$ Scope of the Present Modeling Study}

This present study concentrated on creating software to derive the modeling coefficients from the gasoline distillation data and specific gravity. The properties of different gasolines could then be easily incorporated into ethanol-gasoline blend models.

This part of the current work created this software in the form of Excel spreadsheets using Visual Basic subroutines. The software was then validated using published data and some data derived specifically for this project. After validation it was used to model the fuel tank flammability of the various blends of interest being tested in the experimental part of the current project. Reference 8 provided measured vapor pressure for an air-free gasoline with known properties. The removal of dissolved air from the gasoline in that work avoided the problem of unknown air effects. This issue will be discussed below in connection with the other tests carried out as part of this study.

The experimental data from that study consisted of known masses of the test gasoline contained in a container of known volume, held until there was phase equilibrium between the final liquid volume and its vapor at the test temperature. To assess the implementation of the gasoline model created in this project, the properties of the test gasoline in that 1986 study were inserted into the Excel spreadsheet. The spreadsheet provides the coefficients needed to represent the gasoline in the basic vapor pressure and molecular weight equations.

One aspect of the model for this and all the other cases of interest in the present project is that the final distribution between liquid and vapor is unknown. The model must be incorporated into a larger computer program that will iteratively find the quantity of liquid and vapor pressure in the known volume that meets the phase equilibrium requirements. In the present study, a commercial equation solving software package (TK Solver) was used for these determinations. Figure 9 shows the results for a test temperature of $0^{\circ} \mathrm{C}$.

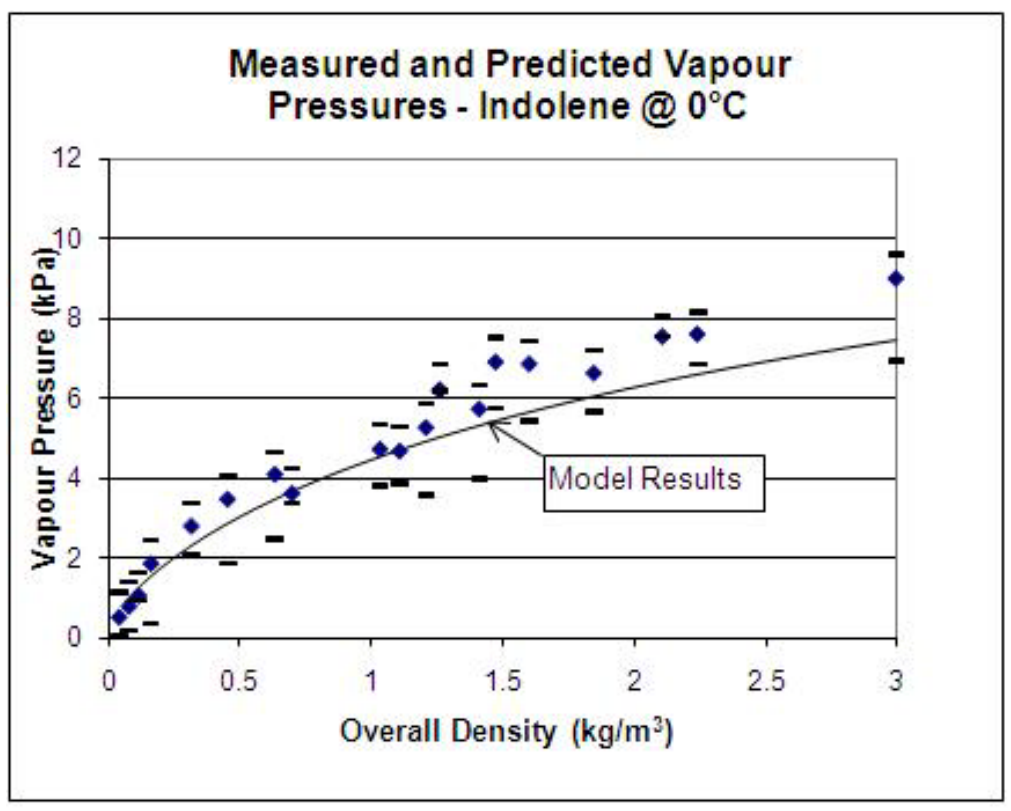

Figure 9. Measured and Predicted Vapor Pressures - Indolene @ 0 $\mathrm{C}$ 
In this figure, overall density is simply the mass of fuel injected divided by the internal volume of the test chamber. The equilibrium mixtures contain more liquid and less vapor mass towards the right, i.e., at higher densities. Points to the left represent mixtures in which there is mostly vapor at equilibrium, whereas points towards the right correspond to cases in which most of the fuel mass is in the form of liquid.

As can be seen, the model generally simulates the fuel behavior well. However, points to the right, where most fuel is in the liquid phase, seem a bit underpredicted, although most are within the uncertainty of the measurements. The model seems to predict slightly lower vapor pressures than those measured. This is important for the present study since the cases of particular interest are those in which fuel tanks are 5\% full or more. Even when only 5\% filled with liquid, the overwhelming mass of fuel is in the liquid phase. The mass fraction of fuel in the form of vapor is well below $1 \%$ in all cases studied here.

It is not surprising that the model underpredicts vapor pressure at very low values of mass fraction evaporated. This corresponds to the left-most portion of the distillation curve, the region of most volatile components - the so-called "light ends." These components are part of the loss in the distillation test and greatly influence the vapor pressures when they are still in the liquid phase, before being depleted as evaporation proceeds. This will be discussed later. It is noteworthy that despite the fact that less than $1 \%$ of the fuel is vaporized, the small differences in mass fraction evaporated result in substantial changes in vapor pressure due to the impact of small quantities of light ends.

Based on the generally good results such as those shown in the above figure, it was concluded that the implementation of the model was successful. A caveat is that the most volatile components are expected to be somewhat underpredicted.

\section{$9 \quad$ Validation Using the Specific Tests and Test Fuels}

In this project, the gasoline model is critical since it provides highly volatile components that determine the vapor pressure and flammability. To assess the gasoline model implementation further, particularly as it affects ethanol blends, tests were carried out in a Grabner apparatus at the Alberta Research Council (ARC) using the conditions corresponding to DVPE and Reid vapor pressure (RVP) tests, but measuring vapor pressures over a range of temperatures rather than merely at $37.8^{\circ} \mathrm{C}\left(100^{\circ} \mathrm{F}\right)$. A winter grade, oxygenate-free gasoline was selected, and a blend was then made up using this base gasoline and $10 \%$ by volume of a commercial denatured ethanol. The properties of the two fuels are included in Appendix D.

The apparatus is evacuated prior to the tests. As is the case for the standard DVPE and RVP tests, a known volume of liquid fuel is inserted into a measuring chamber having a volume five times larger than the initial liquid volume. This provides the nominal vapor liquid ratio (V/L) of 4:1. However, once some liquid fuel evaporates to produce phase equilibrium at the test temperature, the actual $\mathrm{V} / \mathrm{L}$ ratio is less than the nominal $4: 1$ and must be determined iteratively by the software. Once equilibrium is attained at any given temperature, the known volume contains not only an unknown quantity of liquid fuel and its vapor in equilibrium at the test 
temperature, but also a quantity of air that also contributes to the measured total pressure. This air was initially present in the chilled liquid fuel but leaves the liquid phase such that it is in equilibrium with the dissolved air remaining in the liquid phase. Therefore, the measurement of total pressure in the chamber gives the sum of the vapor pressure of the fuel plus the pressure of that part of the air originally dissolved in the liquid fuel that came out of solution to achieve the final equilibrium conditions.

As part of the procedure for the determination of an equivalent of the RVP/DVPE [9], a correlation is provided to correct the measured total pressure at the DVPE/RVP temperature of $37.8^{\circ} \mathrm{C}\left(100^{\circ} \mathrm{F}\right)$ to the DVPE or RVP measured in the conventional apparatus. This is essentially the correction for dissolved air in the Grabner apparatus, but that applies only to the DVPE test temperature. Due to the conditions in the RVP test, the effect of dissolved air on measured pressure is negligibly small.

To compare the model with the measured values, a dissolved air correction was made; this used the empirical data for air solubility in hydrocarbons given in Rose and Cooper [10]. For this calculation it was assumed that the original sample (stored at about $0^{\circ} \mathrm{C}$ ) was saturated with air. Various amounts of this air present in the original liquid introduced to the fixed volume of the apparatus then come out of solution at different temperatures, as described above. The program used to determine the final distribution of fuel between liquid and vapor phases also incorporated a calculation of the amount of air in the two phases at the known final total volume and temperature.

Figure 10 shows the results. As discussed above, the model tends to underpredict the vapor pressure. It is derived from the D86 distillation curve, which is heavily influenced by the lightest, most volatile components. These constituents are only coarsely captured in the standard distillation data. Note that the dissolved air correction corresponds closely to the DVPE/RVP correction known to apply at $37.8^{\circ} \mathrm{C}$. This gives confidence that the correction to the measured pressure to account for dissolved air is valid.

To allow the model to better represent the volatile components, it was adjusted to give the measured DVPE/RVP resulting from the specified ASTM correction. This resulted in the curve shown. The DVPE-matched model agrees very well with the measured vapor pressure of this gasoline as corrected for dissolved air. 


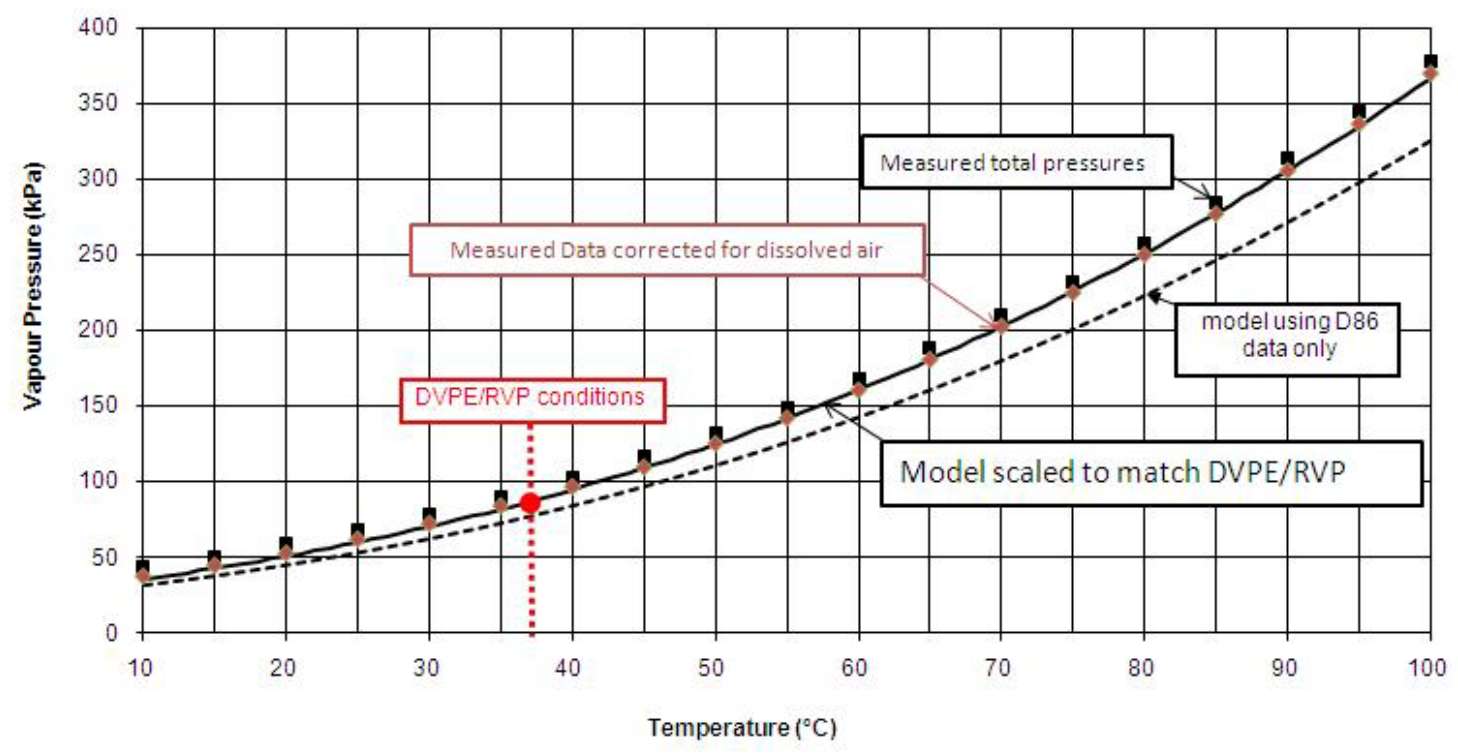

Figure 10. Measured and Predicted Vapor Pressure of ARC Gasoline (V/L=4)

Having matched the model to the ARC gasoline, the model was then set up for the E10 mixture. The denaturant was composed of hydrocarbons that make up approximately 5\% of the ethanol. The denaturant was simply lumped with the gasoline and assumed to have similar properties for this purpose. The vapor pressure of this blend (including the adjustment to match the gasoline DVPE) was then compared to the measured results in the Grabner temperature sweep for the E10 blend. Figure 11 shows the results.

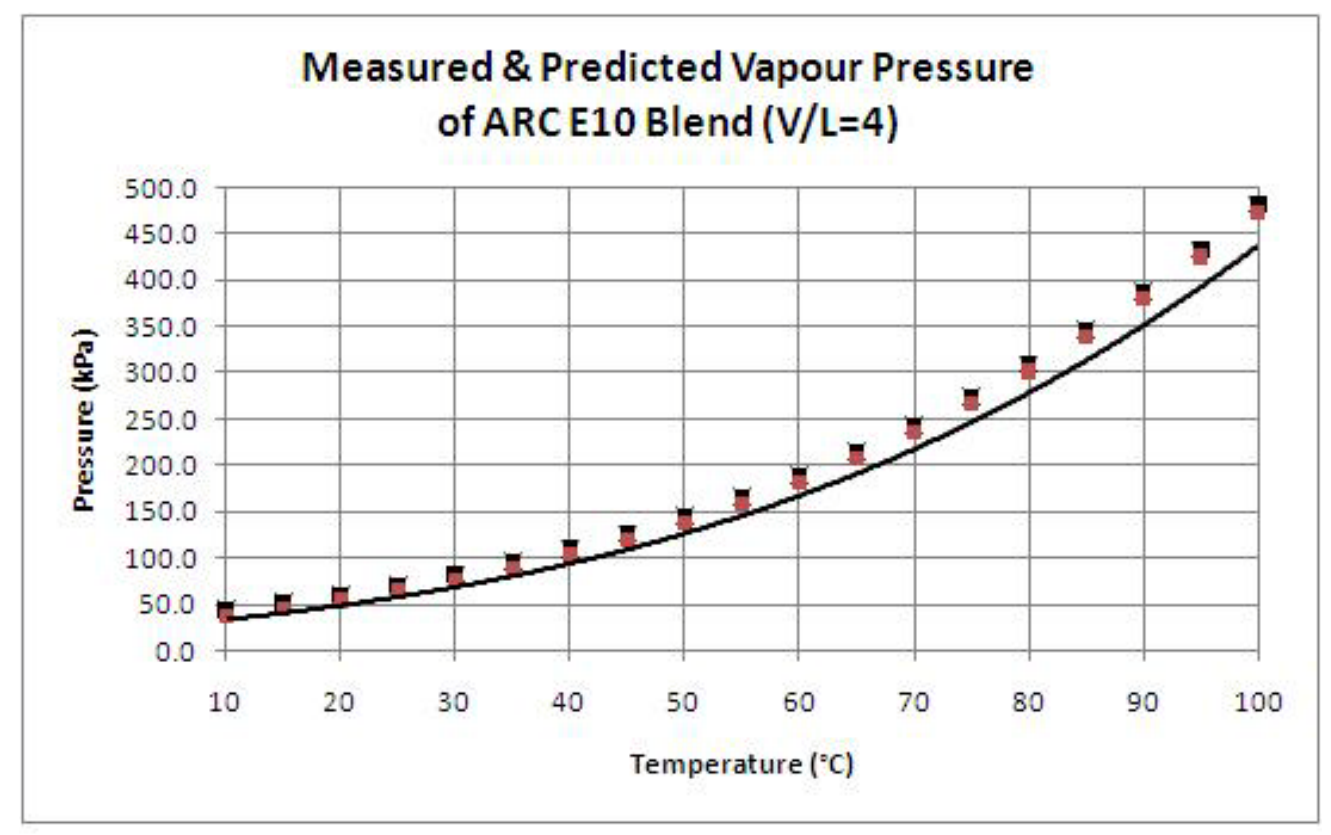

Figure 11. Measured and Predicted Vapor Pressure of ARC E10 Blend (V/L=4) 
As can be seen, the results are reasonably good, but the model is underpredicting the vapor pressure of the E10. This can only be the result of the non-ideality model being used. In the absence of experimental data for other proportions of ethanol and this gasoline, this part of the blend model cannot realistically be assessed and adjusted using the two ARC fuels. However the laboratory blend data discussed below covers a range of blends from E55-E83, allowing the nonideality model to be assessed and adjusted.

\section{Modeling the Laboratory Blends}

As part of the project, the properties of the base gasoline and those of five laboratory blends were supplied. Appendix B gives the data received.

Inserting the gasoline D86 and specific gravity data into the model then allowed the a priori prediction of DVPE as a means to assess the accuracy of the model without adjustments. As expected, the model again underpredicted the DVPE. Adjusting the model so that the DVPE was matched to the Marathon base gasoline then gave results that overpredicted the DVPE of the high ethanol blends supplied in this project. The form of the Margules method used for determining the activity coefficients was as follows:

$$
\begin{aligned}
& \gamma_{\text {gasoline }}=e^{\frac{A X_{\text {ethanol }}^{2}}{T}} \\
& \gamma_{\text {ethanol }}=e^{\frac{A X_{\text {gasoline }}^{2}}{T}}
\end{aligned}
$$

where

$$
\begin{aligned}
& \gamma_{\text {gasoline }}=\text { activity coefficient of the gasoline } \\
& \gamma_{\text {ethanol }}=\text { activity coefficient of the ethanol } \\
& A=\text { the Margules "constant" } \\
& X_{\text {gasoline }}=\text { mole fraction of gasoline in the blend } \\
& X_{\text {ethanol }}=\text { mole fraction of ethanol in the blend }
\end{aligned}
$$

and the Margules constant is itself given by

$$
A=C_{1}+C_{2} \times\left(\frac{X_{\text {ethanol }}}{1-X_{\text {ethanol }}}\right) \text {. }
$$

In the original published model [3], the measured vapor pressures of various blends of methanol and ethanol were used to derive values of $C_{1}$ and $C_{2}$ of 600 and 5.25, respectively. The DVPE reflects the non-ideality of the blends, so it can used to assess the non-ideality coefficients. In the case of the laboratory blends, the measured DVPE values were used to determine the values of these coefficients to be used in predicting the flammability of these blends. It was found that a good fit to the DVPE values could be obtained using: 


$$
\begin{aligned}
& C_{1}=600 \\
& C_{2}=-2.27
\end{aligned}
$$

With the gasoline model matched to the DVPE of the base gasoline, and the Margules nonideality equations modified as described above, the DVPE predictions were as shown in Figure 12.

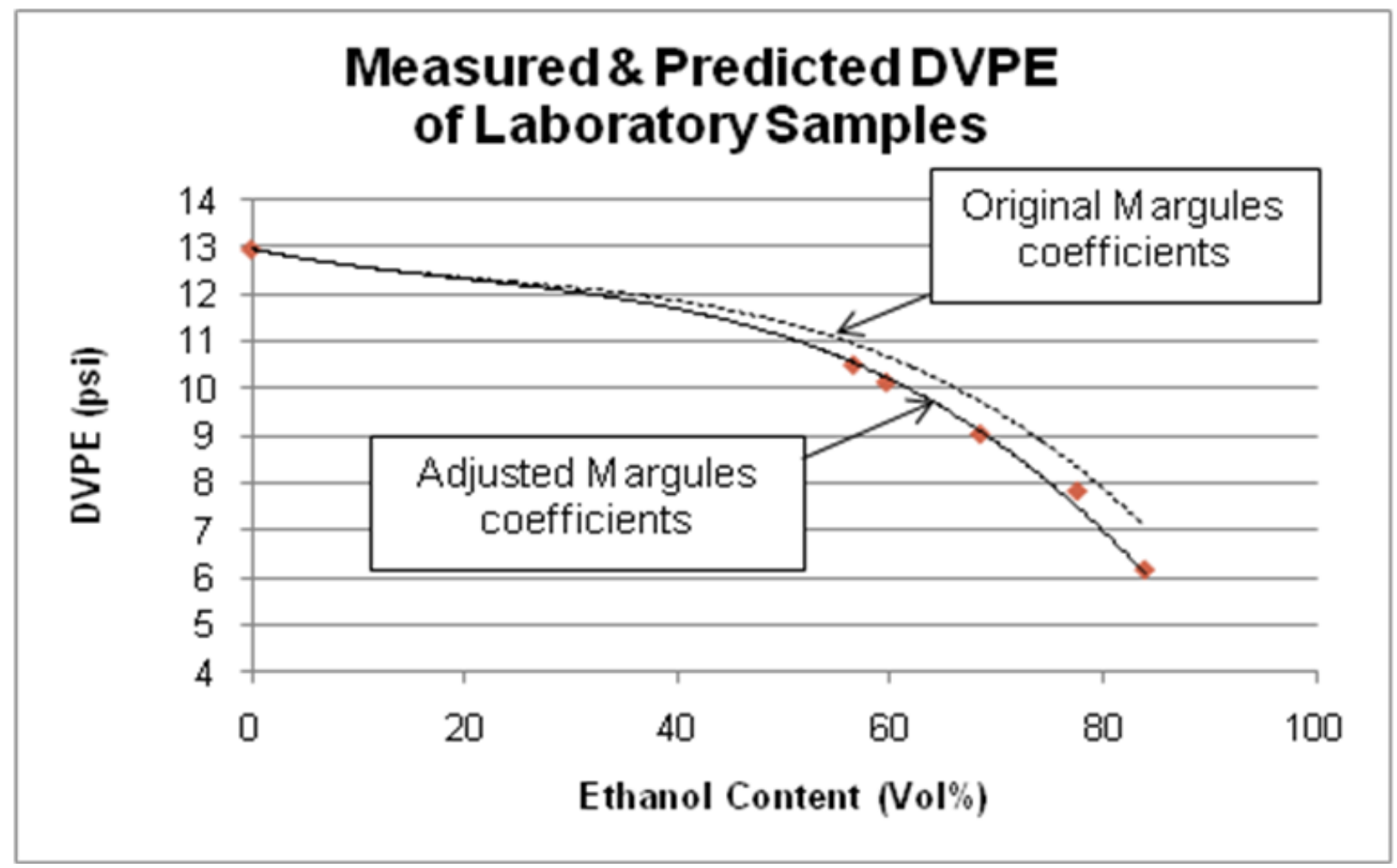

Figure 12. Measured and Predicted DVPE of Laboratory Samples

This matching cannot be considered definitive, even for this particular gasoline, because there are no measured data for low alcohol blends. However, it can be seen in this figure that the vapor pressure is accurately modeled. The model could now be used to predict the flammability of fuel tank headspace vapors with reasonable confidence.

\section{Comparison of Predicted and Measured Flammability of Fuel Tank Headspace Vapors}

Using the conventional published values of flammability limits for the alcohol and gasoline components as described in Appendix $\mathrm{C}$, the model was used to predict the rich flammability limits as functions of ambient temperature for the various laboratory blends in the headspace vapors of a fuel tank filled to $5 \%$ of its capacity. These predicted temperature limits were then compared to the measured limits found in the testing part of this project. The results are shown in Figure 13. 


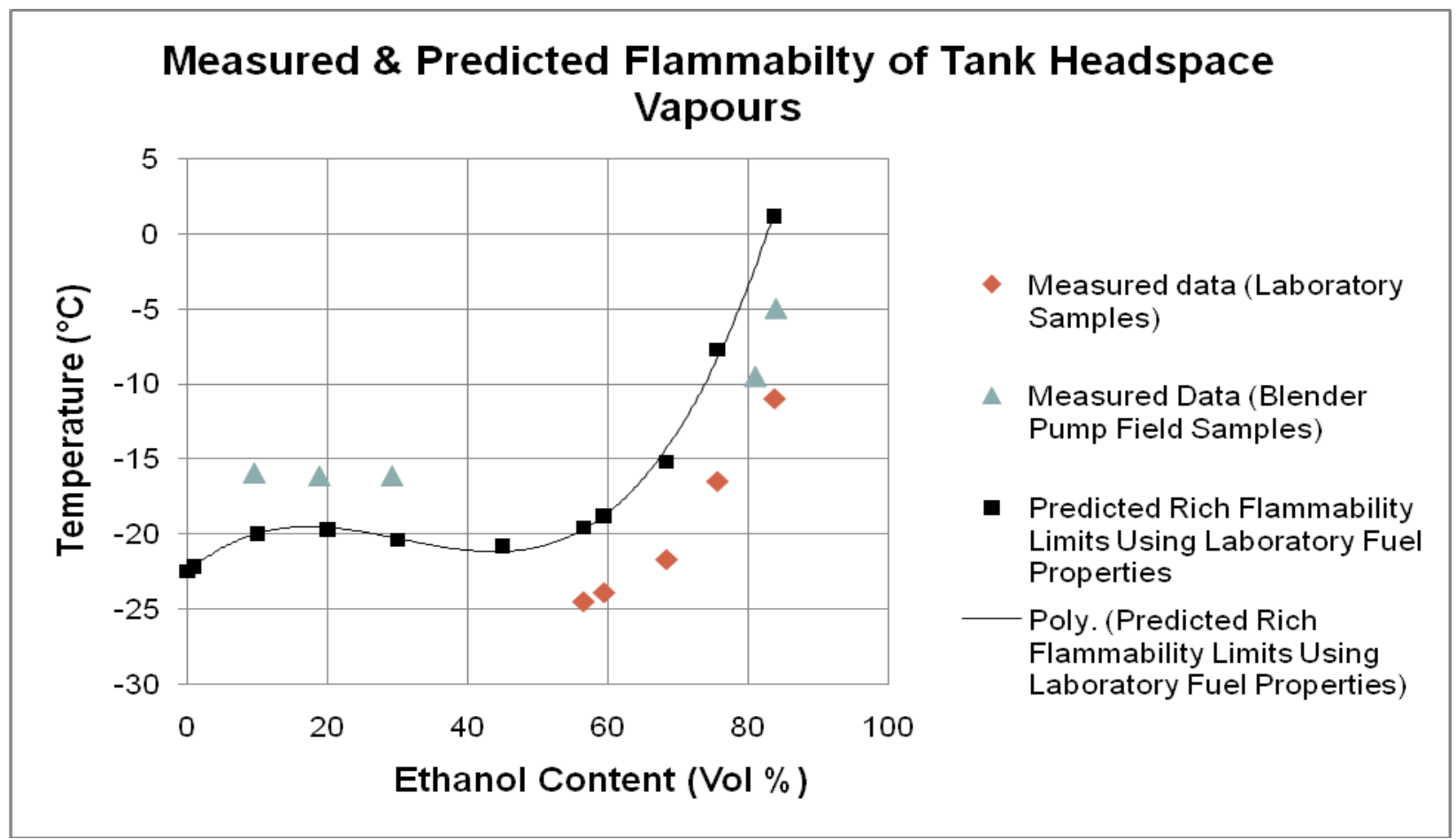

Figure 13. Measured and Predicted Flammability of Tank Headspace Vapors

Since the model used the properties of the laboratory blend base gasoline, only the measured results for the laboratory blends can be expected to be reflected properly in the predictions.

Overall, the limit temperatures predicted by the model are somewhat higher than the measured values, but the trend of the data is very well represented. The lower measured temperatures compared to the predictions are ascribed primarily to the differences in the experimental techniques used to derive conventional published flammability compared to the test conditions.

Published flammability data is normally measured in large-diameter flame tubes, to avoid wall effects, under ideal conditions that promote combustion, such as vertically upward flame propagation. The reason for such conditions is to provide worst-case scenarios for the safety concerns that have been the primary motivator for the tests. In the tests here, or in the real case of a vehicle fuel tank, the apparatus and conditions are quite different. Wall effects, ignition source location and ignition energy all play a role in making the mixtures harder to ignite in the tests than expected based on the standard flammability data. It is to be expected that a given mixture will not be ignited at the predicted rich limit but rather at some lower temperature. This is indeed what is seen in the figure.

The trend shown for the laboratory fuels with the range of the measurements is a very good match for that of the experimental data. However, there is slight hump on the left of the predicted curve. This is due to the non-ideality effects. It may well be a real phenomenon due to the characteristics of these blends of polar and nonpolar molecules. On the other hand, the shape predicted for the low alcohol blends may be merely an artefact of the particular model used to account for non-ideality. To ascertain which is the case, actual combustion tests would need to 
be carried out for some lower ethanol blends in that region. However, the difference in the predicted rich limit temperatures with or without the hump is fairly small in any case, so this anomaly has little practical impact, whether it is real or only mathematically imagined.

It is clear that the model can indeed predict the correct trend and ranking of fuels when the gasoline component is correctly represented. The data from the blender pump field sample tests also follow the general trend of the model, but too much significance should not be placed on this because of the unknown differences in the base gasolines used in those blends.

\section{Conclusions from the Modeling Study}

1. When some basic properties of the base oxygenate-free gasoline are known, then the mathematical model developed in this study can be used to compare the flammability characteristics of various gasoline-ethanol blends quite satisfactorily. The model requires ASTM D86 distillation data, D4052 specific gravity, and D5191 DVPE of the base oxygenate-free gasoline and the percentages of ethanol and gasoline in the blend.

2. The use of conventional flammability data leads to the prediction of higher rich limit temperatures than those actually measured in the experimental apparatus used in the study. Although an adjustment might be made to better match the predictions to the measurements, this is unlikely to be worthwhile, since it would again be apparatus dependent and not necessarily applicable to other conditions. Rather, the model is useful in comparing blends to each other to assess their relative hazards.

3. Since the project had sufficient gasoline data only for the laboratory blends tested for flammability, further work is needed to compare ethanol blends containing different gasoline base stock. This would allow an assessment to be made of the reliability of the model for comparing the relative hazards of different fuel sources.

4. Since most gasolines now contain some oxygenates, the distillation (D86) data for the base gasoline alone is often not available. Given the success of the model, it would be desirable to attempt to devise a technique for extracting the necessary gasoline data from the D86 data of a low alcohol blend. That is not trivial, but comparisons such as those made of the special E0 and E10 fuels studied in this project may allow such a technique to be developed, thereby making the model much more accessible for use by others. 


\section{OVERALL CONCLUSIONS AND RECOMMENDATIONS}

\section{Conclusions from the Experimental Study}

1. Both of the E85 field samples that were tested had vapor pressure values well below the minimum Class 3 specifications of ASTM D5798-09. One of these fuels produced flammable vapors over the entire Class 3 temperature range $\left(-5^{\circ} \mathrm{C}\right.$ and below). The other fuel produced flammable vapors at $-10^{\circ} \mathrm{C}$ and below. These results indicate that at least some of the ethanol fuels that are currently available when and where Class 3 conditions exist are likely to produce flammable vapors within the ambient temperature range where they are used.

2. Two mid-level ethanol blends (E20 and E30) were tested. These field samples were produced by a blender pump that mixed E10 (the base gasoline available at that location) with E85. No significant differences could be measured between vapor flammability limits of the E20-E30 samples and the E10 sample they were produced from. These results indicate that mid-level blends in this range are unlikely to significantly increase the risk of producing flammable vapors over that of the base gasoline used for the blends.

3. Laboratory fuel blends of E55-E83 were produced by blending denatured ethanol with a single type of winter volatility gasoline. The flammability limits of these fuels showed a nonlinear relationship with both ethanol content and vapor pressure. Consequently, reducing the ethanol content of the fuels from typical E85 levels ( $80 \%$ or more) initially produced substantial reductions in the temperature at which it was possible for flammable vapors to form. Reductions in ethanol content below about $60 \%$ had a smaller relative impact on the flammability limits.

4. The laboratory fuel blends were produced from a "typical" winter volatility gasoline, with a DVPE value of $89 \mathrm{kPa}$. None of the blends produced from this gasoline could simultaneously meet the ASTM D5798 requirements for minimum vapor pressure (66 $\mathrm{kPa}$ ) and minimum ethanol content $(70 \%)$. The vapor pressure data for the blends indicated that a reduction in ethanol content to about $65 \%$ would be needed to achieve the minimum vapor pressure specification. The flammability data trends suggest that blends with ethanol content in this region would provide a favorable trade-off between avoiding the formation of flammable vapors and maximizing the ethanol content of the fuel.

5. Comparisons of the flammability results of the field and laboratory samples indicate that vapor pressure (DVPE) alone does not adequately predict the flammability of the fuel tank vapors formed at low temperatures. The properties of the hydrocarbon portion of the fuel must be considered as well.

6. It is recommended that further testing be carried out with laboratory fuels to examine the effects of gasoline volatility on the vapor flammability of the ethanol/gasoline blends. Flammability results over a wider range of ethanol content levels (including base gasoline without ethanol) are needed to elucidate the interactions between ethanol content, gasoline volatility, blend vapor pressure, and vapor flammability. 


\section{Conclusions from the Modeling Study}

1. When some basic properties of the base oxygenate-free gasoline are known, then the mathematical model developed in this study can be used to compare the flammability characteristics of various gasoline-ethanol blends quite satisfactorily. The model requires ASTM D86 distillation data, D4052 specific gravity, and D5191 DVPE of the base oxygenate-free gasoline and the percentages of ethanol and gasoline in the blend.

2. The use of conventional flammability data leads to the prediction of higher rich limit temperatures than those actually measured in the experimental apparatus used in the study. Although an adjustment might be made to better match the predictions to the measurements, this is unlikely to be worthwhile, since it would again be apparatus dependent and not necessarily applicable to other conditions. Rather, the model is useful in comparing blends to each other to assess their relative hazards.

3. Since the project had sufficient gasoline data only for the laboratory blends tested for flammability, further work is needed to compare ethanol blends containing different gasoline base stock. This would allow an assessment to be made of the reliability of the model for comparing the relative hazards of different fuel sources.

4. Since most gasolines now contain some oxygenates, the distillation (D86) data for the base gasoline alone is often not available. Given the success of the model, it would be desirable to attempt to devise a technique for extracting the necessary gasoline data from the D86 data of a low alcohol blend. That is not trivial, but comparisons such as those made of the special E0 and E10 fuels studied in this project may allow such a technique to be developed, thereby making the model much more accessible for use by others. 


\section{References}

1. Gardiner, D.P., Bardon, M.F., and Pucher, G., An Experimental and Modeling Study of the Flammability of Fuel Tank Headspace Vapors from High Ethanol Content Fuels, Subcontract Report No. NREL/SR-540-44040, produced for the DOE National Renewable Energy Laboratory under Subcontract No. XCI-5-5505-01, September 2008.

2. Persson, H., Bremer, P., Rosell, L., Arrhenius, K., and Lindstrom, K., Fuel Vapor Composition and Flammability Properties of E85, SP Report 2007:39, Brandteknik, Boras, 2007.

3. Vaivads, R.H., Bardon, M.F., Rao, V.K., and Battista, V., "Flammability Tests of Alcohol/Gasoline Vapors," SAE Paper \#950401, Society of Automotive Engineers, Warrendale, PA, 1995.

4. Vaivads, R., Rao,V.K., Bardon, M.F., and Battista, V., "Volatility and Flammability of Variable Fuel Vehicle Tank Contents," SAE paper \# 932776, presented at the Fuels \& Lubricants Meeting and Exposition, Philadelphia, Oct, 18-21, 1993.

5. Vaivads, R., Bardon, M.F., Rao,V.K., and Battista, V., "Flammability of Alcohol-Gasoline Blends in Fuel Tanks," presented at the $4^{\text {th }}$ International Symposium on Fire Safety Science, Ottawa, June 13-17, 1994.

6. "Standard Specification for Fuel Ethanol (Ed75-Ed85)for Automotive Spark-Ignition Engines," ASTM D5798-09, ASTM International, West Conshohocken, PA, February 2009.

7. Lattin, J., Carroll, J.D., and Green, P.E., Analyzing Multivariate Data, Thomson, Brooks and Cole, 2003.

8. Bardon, M.F., Rao,V.K., Vaivads, R., and Evans, M.J.B., "Measured and Predicted Effect of the Extent of Evaporation on Gasoline Vapour Pressure." J. Inst. Energy, v59, n441, Dec. 1986.

9. "Standard Test Method for Determination of Vapor Pressure of Crude Oil: $\mathrm{VPCR}_{\mathrm{x}}$ (Expansion Method)," Test D6377-08, ASTM International, West Conshohocken, PA, 2008.

10. Technical Data on Fuel, J.W. Rose and J.R. Cooper, Eds., $7^{\text {th }}$ Edition, British National Committee, World Energy Conference, London.

11. Bardon, M.F., and Rao,V.K., "Calculation of Gasoline Volatility”. J.Inst. Energy, v57, 343348, Sept 1984

12. Rao, V.K., and Bardon, M.F., "Estimating the Molecular Weight of Petroleum Fractions," Ind. Eng. Chem., Process Des. Dev., v27, n2, April 1985.

13. Wilhoit, R.C., and Zwolinski, B.J., "Physical and Thermodynamic Properties of Aliphatic Alcohols, , J. Phys. Chem. Ref. Data, v2 Supp. 1, 1973, pp. 1.40-1.54. 
14. Bardon, M.F., Nicks, G.W., Rao,V.K., and Vaivads, R., "A Vapour Pressure Model for Methanol/Gasoline M85 Blends," Paper \# 870366, Trans SAE, J Fuels and Lubricants, v96, Section 5, pp. 38-45, 1987.

15. Zabetakis, M.G., "Flammability Characteristics of Combustible Gases and Vapors," U.S. Bureau of Mines, Bulletin 621, Washington, 1965. 


\section{APPENDIX A \\ Properties of Field Samples}

\begin{tabular}{|c|c|c|c|c|c|c|c|}
\hline & Result & Rep\# & E85 MN & E85 SD & E30 SD & E20 SD & E10 SD \\
\hline & ProjName & & MISC & MISC & MISC & MISC & MISC \\
\hline & ProjSeq & & 55326 & 55350 & 55349 & 55348 & 55347 \\
\hline & SmplType & & E85 & E85 & E30 & $\mathrm{E} 20$ & Gasoline \\
\hline \multirow[t]{4}{*}{ D5191 } & RVP & psi & 6.3 & 5.71 & 8.55 & 8.71 & 8.94 \\
\hline & Ptot & psi & 6.95 & 6.34 & 9.31 & 9.47 & 9.71 \\
\hline & DVPE & psi & 6.16 & 5.57 & 8.44 & 8.59 & 8.82 \\
\hline & CARVP & psi & 6.04 & 5.45 & 8.33 & 8.49 & 8.72 \\
\hline \multirow{2}{*}{ D381 } & UnWshdGm & & 3 & 1.5 & 4.5 & 7.5 & 7.5 \\
\hline & WashdGum & & $<0.5 \mathrm{mg} / 100 \mathrm{~mL}$ & $<0.5 \mathrm{mg} / 100 \mathrm{~mL}$ & $<0.5 \mathrm{mg} / 100 \mathrm{~mL}$ & $<0.5 \mathrm{mg} / 100 \mathrm{~mL}$ & $<0.5 \mathrm{mg} / 100 \mathrm{~mL}$ \\
\hline \multirow{3}{*}{ D4052s } & API@60F & & 49.2 & 49 & 56.7 & 57.6 & 58.9 \\
\hline & SPGr@60F & & 0.7829 & 0.784 & 0.752 & 0.7484 & 0.7433 \\
\hline & Dens@15C & grams/L & 782.5 & 783.6 & 751.7 & 748.1 & 743 \\
\hline \multirow{29}{*}{$\begin{array}{l}\text { D4815 } \\
\\
\\
\\
\\
\end{array}$} & MeOHVol & Vol\% & 0.47 & $<0.2$ & $<0.2$ & $<0.2$ & $<0.2$ \\
\hline & EtOHVol & Vol\% & 80.55 & 83.97 & 29.23 & 18.86 & 9.57 \\
\hline & iPAVol & Vol\% & $<0.2$ & $<0.2$ & $<0.2$ & $<0.2$ & $<0.2$ \\
\hline & tBAVol & Vol\% & $<0.2$ & $<0.2$ & $<0.2$ & $<0.2$ & $<0.2$ \\
\hline & nPAVol & Vol\% & $<0.2$ & $<0.2$ & $<0.2$ & $<0.2$ & $<0.2$ \\
\hline & MTBEVol & Vol\% & $<0.2$ & $<0.2$ & $<0.2$ & $<0.2$ & $<0.2$ \\
\hline & sBAVol & Vol\% & $<0.2$ & $<0.2$ & $<0.2$ & $<0.2$ & $<0.2$ \\
\hline & DIPEVol & Vol\% & 0.22 & $<0.2$ & $<0.2$ & $<0.2$ & $<0.2$ \\
\hline & iBAVol & Vol\% & $<0.2$ & $<0.2$ & $<0.2$ & $<0.2$ & $<0.2$ \\
\hline & ETBEVol & Vol\% & $<0.2$ & $<0.2$ & $<0.2$ & $<0.2$ & $<0.2$ \\
\hline & tPAVol & Vol\% & $<0.2$ & $<0.2$ & $<0.2$ & $<0.2$ & $<0.2$ \\
\hline & nBAVol & Vol\% & $<0.2$ & $<0.2$ & $<0.2$ & $<0.2$ & $<0.2$ \\
\hline & TAMEVol & Vol\% & $<0.2$ & $<0.2$ & $<0.2$ & $<0.2$ & $<0.2$ \\
\hline & TtIVol & Vol\% & 81.54 & 84.2 & 29.42 & 19.01 & 9.62 \\
\hline & MeOHWt & Wt $\%$ & 0.48 & $<0.2$ & $<0.2$ & $<0.2$ & $<0.2$ \\
\hline & EtOHWt & Wt $\%$ & 81.69 & 85.03 & 30.86 & 20.01 & 10.22 \\
\hline & iPAWt & Wt $\%$ & $<0.2$ & $<0.2$ & $<0.2$ & $<0.2$ & $<0.2$ \\
\hline & tBAWt & Wt $\%$ & $<0.2$ & $<0.2$ & $<0.2$ & $<0.2$ & $<0.2$ \\
\hline & nPAWt & Wt $\%$ & $<0.2$ & $<0.2$ & $<0.2$ & $<0.2$ & $<0.2$ \\
\hline & MTBEWt & Wt $\%$ & $<0.2$ & $<0.2$ & $<0.2$ & $<0.2$ & $<0.2$ \\
\hline & sBAWt & Wt $\%$ & $<0.2$ & $<0.2$ & $<0.2$ & $<0.2$ & $<0.2$ \\
\hline & DIPEWt & Wt $\%$ & 0.2 & $<0.2$ & $<0.2$ & $<0.2$ & $<0.2$ \\
\hline & iBAWt & Wt $\%$ & $<0.2$ & $<0.2$ & $<0.2$ & $<0.2$ & $<0.2$ \\
\hline & ETBEWt & Wt $\%$ & $<0.2$ & $<0.2$ & $<0.2$ & $<0.2$ & $<0.2$ \\
\hline & TPAWt & Wt $\%$ & $<0.2$ & $<0.2$ & $<0.2$ & $<0.2$ & $<0.2$ \\
\hline & NBAWt & Wt $\%$ & $<0.2$ & $<0.2$ & $<0.2$ & $<0.2$ & $<0.2$ \\
\hline & TAMEWT & Wt $\%$ & $<0.2$ & $<0.2$ & $<0.2$ & $<0.2$ & $<0.2$ \\
\hline & TtIWt & Wt $\%$ & 28.69 & 29.57 & 10.78 & 6.97 & 3.56 \\
\hline & BenzWt & $\mathbf{W t} \%$ & & 0.13 & 2.06 & 2.58 & 2.9 \\
\hline D5188 & $\mathrm{V} / \mathrm{L}=\mathbf{2 0}$ & $\operatorname{deg} F$ & 152.4 & 156.5 & 131.7 & 131.6 & 130.9 \\
\hline D5453 & Sulfur & ppm & 18.7 & 8.1 & 26.8 & 38.8 & 42.5 \\
\hline \multirow[t]{2}{*}{ D6422 } & AvgTemp & $\operatorname{deg} C$ & 14 & 14 & 14 & 14 & 14 \\
\hline & PassFail & & pass & pass & pass & pass & pass \\
\hline \multirow[t]{17}{*}{ D86 } & IBP & $\operatorname{deg} F$ & 115.9 & 120.7 & 96.8 & 94.1 & 96.4 \\
\hline & Evap_5 & $\operatorname{deg} F$ & 146.8 & 150.6 & 118.3 & 118.1 & 117.0 \\
\hline & Evap_10 & degF & 159.1 & 161.7 & 127.6 & 126.4 & 124.1 \\
\hline & Evap_15 & $\operatorname{deg} F$ & 164.8 & 166.2 & 133.5 & 131.8 & 128.7 \\
\hline & Evap_20 & $\operatorname{deg} F$ & 167.7 & 168.7 & 138.9 & 137.0 & 133.5 \\
\hline & Evap_30 & $\operatorname{deg} F$ & 170.3 & 170.9 & 148.2 & 145.8 & 142.3 \\
\hline & Evap_40 & $\operatorname{deg} F$ & 171.3 & 171.8 & 155.8 & 153.5 & 149.5 \\
\hline & Evap_50 & $\operatorname{deg} F$ & 171.9 & 172.3 & 161.3 & 159.5 & 166.8 \\
\hline & Evap_60 & $\operatorname{deg} F$ & 172.2 & 172.6 & 165.2 & 164.0 & 213.9 \\
\hline & Evap_70 & $\operatorname{deg} F$ & 172.5 & 172.7 & 168.1 & 221.4 & 240.1 \\
\hline & Evap_80 & $\operatorname{deg} F$ & 172.7 & 173.0 & 172.2 & 257.2 & 265.9 \\
\hline & Evap_90 & $\operatorname{deg} F$ & 173.6 & 173.5 & 278.7 & 295.1 & 299.3 \\
\hline & Evap_95 & $\operatorname{deg} F$ & 174.8 & 174.3 & 308.0 & 323.2 & 325.0 \\
\hline & FBP & $\operatorname{deg} F$ & 333.7 & 178.4 & 362.1 & 367.8 & 368.1 \\
\hline & Recoverd & $\mathrm{mL}$ & 98.3 & 98.5 & 97.7 & 97.9 & 98.4 \\
\hline & Residue & $\mathrm{mL}$ & 0.8 & 0.6 & 0.7 & 0.6 & 0.4 \\
\hline & Loss & $\mathrm{mL}$ & 0.9 & 0.9 & 1.6 & 1.5 & 1.2 \\
\hline
\end{tabular}


APPENDIX B

Properties of Laboratory Samples

\begin{tabular}{|c|c|c|c|c|c|c|c|}
\hline Product & E83 & E75 & E68 & E60 & E55 & $\mathrm{EtOH}$ & $\begin{array}{l}\text { 93RBOB } \\
\text { (13 psi) }\end{array}$ \\
\hline Date & $10 / 14 / 2009$ & $10 / 14 / 2009$ & $10 / 14 / 2009$ & $10 / 14 / 2009$ & $10 / 14 / 2009$ & $10 / 12 / 2009$ & $10 / 12 / 2009$ \\
\hline Sample ID & 3057180 & 3057179 & 3057178 & 3057177 & 3057168 & 3055540 & 3055538 \\
\hline D4052 Specific Gravity at $60^{\circ} \mathrm{F}$ & 0.7821 & 0.7748 & 0.7680 & 0.7610 & 0.7584 & 0.7933 & 0.7128 \\
\hline D5191 ASTM DVPE, psi & 6.14 & 7.81 & 9.02 & 10.12 & 10.49 & -- & 12.94 \\
\hline D5501 EtOH, Vol \% & 83.81 & 75.49 & 68.38 & 59.57 & 56.49 & 96.98 & N.D. \\
\hline D5501 MeOH, Vol \% & 0.04 & 0.03 & 0.03 & 0.02 & 0.02 & 0.04 & N.D. \\
\hline E1064 H2O, Wt \% & 0.68 & 0.61 & 0.58 & 0.51 & 0.49 & 0.74 & -- \\
\hline D86 IBP, ${ }^{\circ} \mathrm{F}$ & 118.5 & 107.4 & 96.8 & 93.2 & 90.7 & -- & 78.4 \\
\hline D86 T 10 Evaporated, ${ }^{\circ} \mathrm{F}$ & 165.6 & 161.3 & 154.1 & 146.6 & 144.2 & -- & 110.5 \\
\hline D86 T 20 Evaporated, ${ }^{\circ} \mathrm{F}$ & 169.0 & 167.5 & 164.1 & 161.5 & 159.9 & -- & 140 \\
\hline D86 T 30 Evaporated, ${ }^{\circ} \mathrm{F}$ & 170.4 & 169.6 & 167.1 & 165.4 & 164.6 & -- & 179.2 \\
\hline D86 T 50 Evaporated, ${ }^{\circ} \mathrm{F}$ & 171.6 & 171.9 & 170.3 & 169.0 & 168.4 & -- & 223.9 \\
\hline D86 T 70 Evaporated, ${ }^{\circ} \mathrm{F}$ & 172.2 & 173.1 & 172.2 & 171.8 & 171.3 & -- & 245.9 \\
\hline D86 T 90 Evaporated, ${ }^{\circ} \mathrm{F}$ & 173.1 & 174.7 & 174.6 & 175.2 & 175.2 & -- & 313.9 \\
\hline D86 End Pt, ${ }^{\circ} \mathrm{F}$ & 252.1 & 343.8 & 353.5 & 358.5 & 361.1 & -- & 386.2 \\
\hline D86 Recovery, Vol \% & 98.4 & 97.8 & 97.8 & 97.3 & 97.5 & -- & 97.1 \\
\hline D86 Residue, Vol \% & 0.8 & 0.9 & 1.0 & 1.0 & 1.1 & -- & 0.9 \\
\hline D86 Loss, $\%$ & 0.7 & 1.2 & 1.1 & 1.5 & 1.2 & -- & 2.0 \\
\hline D86 E 200, \% & 98.9 & 98.0 & 96.7 & 95.3 & 94.4 & -- & 36.1 \\
\hline D86 E 300, \% & Not appl. & 98.1 & 96.7 & 95.4 & 94.5 & -- & 87.7 \\
\hline
\end{tabular}




\section{Appendix C \\ Summary of the Models for the Volatility and Flammability of Ethanol- Gasoline Blends}

\section{Volatility Characteristics of Gasolines}

For a pure compound such as a single-component hydrocarbon, the composition and hence molecular weight of the vapor and liquid phases are constant and identical regardless of how much has evaporated, and the vapor pressure and enthalpy of evaporation are functions only of temperature.

The vapour pressure of pure compounds can be adequately described for most practical purposes by a simple equation such as the classical Clausius-Clapeyron equation, as follows:

$$
P_{\text {sat }}=C_{1} \exp \left(-C_{2} / T\right)
$$

where

$$
\begin{array}{ll}
P_{\text {sat }} & =\text { equilibrium saturation pressure } \\
T & =\text { absolute temperature } \\
C_{1} \text { and } C_{2} & =\text { constants for any given pure substance }
\end{array}
$$

On the other hand, commercial gasolines and other refinery products are mixtures of hundreds of individual pure hydrocarbon compounds. As a result, the compositions of the liquid and vapour phases vary continuously as the fuel evaporates. Light volatile fractions evaporate first, followed progressively by the heavier molecular weight compounds in the fuel.

Modeling real fuels can in principle be done by expressing the vapour pressure of each of the hundreds of components using Equation 1 with the constants applicable for each component, and then combining all components using Raoult's Law for ideal mixtures, namely:

$$
P_{\text {fuel sat }}=\sum_{i=1}^{i=N} X_{i} P_{i \text { sat }}
$$

where

$P_{\text {fuel sat }}=$ total vapour pressure of the hydrocarbon blend

$X_{i} \quad=$ mole fraction of component $i$ in the liquid phase of the blend at equilibrium

$P_{i \text { sat }} \quad=$ equilibrium saturation pressure of component $i$ alone

In practice, this requires the detailed composition of the fuel blend to be known, and the constants $C_{1}$ and $C_{2}$ for each component to be available. Equation 2 can then be used to find the vapour pressure of the blend at some given mass fraction evaporated (say, 20\%). However, iteration is required because the mole fractions of each compound in the two phases are different from each other and are no longer the same as that of the initial mixture before evaporation occurred. A computer model can be developed on this basis, but the code for such a model tends to be large and relatively slow, and the exact composition of each blend to be evaluated must be known. Non-ideal mixtures, such as blends of gasoline and ethanol, further complicate the process. 
For many practical analyses, a simple and fast model is needed to allow blend volatility to be calculated. It has been shown $[11,12]$ that hydrocarbon blends such as gasoline can be modeled quite satisfactorily for many purposes by describing their vapor pressure and other properties using the form of the Clausius-Clapeyron equation but using appropriate polynomial functions instead of the two constants $C_{1}$ and $C_{2}$ as follows:

$$
P_{\text {sat }}=f_{1} \exp \left(-f_{2} / T\right)
$$

where

$$
\begin{array}{ll}
P_{\text {sat }} & =\text { equilibrium saturation pressure } \\
T & =\text { absolute temperature } \\
f_{1} \text { and } f_{2}= & \text { functions of the extent of evaporation defined by } V F \text { where } \\
& V F=\text { mass fraction of the mixture in the vapour phase }
\end{array}
$$

Equation 3 essentially separates the effects of temperature, expressed directly in the exponential term of this Clausius-Clapeyron format, from the extent of evaporation, contained exclusively within the functions $\mathrm{fl}$ and $f_{2}$. These latter two functions can be expressed as polynomials in the vapour fraction, $V F$. References [11] and [12] showed how the functions can be derived using only the ASTM D86 distillation data for the mixture and its specific gravity.

Despite the drastic simplification of using Equation 3 to represent the complex evaporative behaviour of a hydrocarbon mixture, experimental measurements [9] showed that this method gave quite satisfactory predictions of hydrocarbon vapour pressure over a range of temperatures from $0^{\circ} \mathrm{C}$ to $40^{\circ} \mathrm{C}$. Subsequent measurements to temperatures as low as $-40^{\circ} \mathrm{C}$ showed that the method worked well over the entire range $\left(-40^{\circ} \mathrm{C}\right.$ to $\left.+40^{\circ} \mathrm{C}\right)$ of interest for ambient conditions in North America.

\section{Volatility Characteristics of Ethanol}

The ethanol vapour pressure is modeled using the Antoine Equation:

$$
\log _{10} P_{\text {sat ethanol }}=A-B /(C+T)
$$

The values of the coefficients used for ethanol were taken from Wilhoit and Zwolinski [13].

\section{Volatility Characteristics of Gasoline/Alcohol Blends}

Based on the success of this simplified approach to modeling hydrocarbon blends, the method was then extended to encompass blends of methanol or ethanol with gasoline. The approach [14] was to treat any blend of an alcohol with a hydrocarbon as if it were a pseudo-binary mixture, that is, a mixture of a single hydrocarbon component represented by the model described above (Equation 3), and the alcohol, represented by the Clausius-Clapeyron or Antoine equations as usual for pure compounds.

Such blends are somewhat more complicated to model than those involving only hydrocarbons, because mixtures of strongly polar compounds such as alcohols do not form ideal mixtures with nonpolar compounds such as hydrocarbons. Thus Raoult's Law (Equation 2) does not apply as 
written and a modification to account for the non-ideality of the resulting alcohol/hydrocarbon mixture was used. For a blend such as $85 \%$ ethanol and gasoline (E85), this has the form:

$$
P_{E 85}=\gamma_{g} X_{g} P_{g s a t}+\gamma_{e} X_{e} P_{e s a t}
$$

where

$P_{E 85} \quad=$ equilibrium saturation pressure of the E85 mixture

$\gamma_{g} \quad=$ activity coefficient for gasoline in the blend

$\gamma_{e} \quad=$ activity coefficient for methanol in the blend

$X_{g} \quad=$ mole fraction of gasoline in the liquid phase

$X_{e} \quad=$ mole fraction of ethanol in the liquid phase

$P_{\text {gsat }} \quad=$ saturated vapour pressure of the gasoline

$P_{\text {esat }} \quad=$ saturated vapour pressure of the methanol

Note that $X_{g}$ and $X_{e}$ as well as $P_{g s a t}$ vary continuously as the fuel evaporates. Furthermore, at any point in the evaporation process, when the overall vapour fraction $V F_{E 85}$ is some fixed value (between 0 and 1), the vapour fraction of the gasoline component $V F_{g}$ is different from that of the ethanol $V F_{e}$ and both are different from $V F_{E 85}$. Representative values for the two activity coefficients were determined for use with gasoline alcohol blends as part of that and subsequent work. Since the mole fractions of each of the two components in the liquid phase are not known a priori for some overall value of vapour fraction for the blend, iteration is required to determine the vapour pressure and other volatility characteristics needed, such as the molecular weight of the vapour phase. This makes the model more complex to use but still much simpler than the more rigorous methods. Experimental measurements over the temperature range $-40^{\circ} \mathrm{C}$ to $+40^{\circ} \mathrm{C}$ again showed that the model works quite satisfactorily for predicting the volatility properties of such pseudo-binary alcohol/gasoline blends [14].

\section{Modeling the Flammability Characteristics of Gasoline/Alcohol Blends}

The volatility model allows the composition of the vapour phase to be determined at any given temperature and fuel fill level in a fuel tank. Using published flammability for the gasoline and ethanol [15], combined using the LeChatelier mixing rule, then allows the resulting flammability of the vapour phase to be determined. Further details and other references are given in the report submitted for the first phase of this project [1]. 


\section{APPENDIX D \\ Alberta Research Council - Fuels \& Lubricants Report of Analysis}

Alberta Research Council Fuels \& Lubricants
250 Kari Clark Road, Edmonton, Alberta, Canada T6N IE4
Certified by the Standards Council of Canada as an Accredited Testing Organization complying
with the requirements of ISO/IEC 17025 for specific tests registered with the Council
Report of Analysis
This report may only be reproduced in its entirety
Client: NEXUM Research Corporation
15 Miller Place
Amherstview, ON, K7N $2 \times 6$

Alberta Research Council Fuels \& Lubricants
fied by the Standards Council of Canada as an Accredited Testing Organization complying
C 17025 for specific tests registered with the Council

FUELS \& LUBRICANTS

INDESITIAL SUPPORT

Page 1 of 2

Report GO-2009-5204 to 5205

\begin{tabular}{|c|c|c|c|c|c|}
\hline $\begin{array}{l}\text { Lab Sample } \\
\text { Number }\end{array}$ & $\begin{array}{l}\text { Client's Reference } \\
\text { Sample Type; Date Received }\end{array}$ & Method & Analysis & Result & Notes \\
\hline \multirow[t]{18}{*}{ GO-2009-5204 } & $\begin{array}{l}\text { Non-oxygenates Winter Grade Gasoline } \\
\text { (M798) }\end{array}$ & & & & \\
\hline & Motor Gasoline; 24-Aug-2009 & & & & \\
\hline & & ASTM D86 & Distillation, \% Evaporated, ${ }^{\circ} \mathrm{C}$ (corrected) & & \\
\hline & & & I.B.P. & 30.4 & \\
\hline & & & $5 \%$ & 35.1 & \\
\hline & & & $10 \%$ & 44.9 & \\
\hline & & & $20 \%$ & 64.4 & \\
\hline & & & $30 \%$ & 85.3 & \\
\hline & & & $40 \%$ & 96.9 & \\
\hline & & & $50 \%$ & 102.4 & \\
\hline & & & $60 \%$ & 106.3 & \\
\hline & & & $70 \%$ & 112.0 & \\
\hline & & & $80 \%$ & 120.5 & \\
\hline & & & $90 \%$ & 138.9 & \\
\hline & & & E.P. & 194.6 & \\
\hline & & & Residue, \% & 0.8 & \\
\hline & & & $\%$ Evaporated at $300^{\circ} \mathrm{F}$ & 93.1 & \\
\hline & & ASTM D4052 & Density, kg/m3, @ $15^{\circ} \mathrm{C}$ & 714.2 & \\
\hline
\end{tabular}




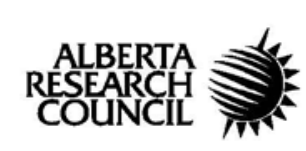

Client: NEXUM Research Corporation

15 Miller Place

Amherstview, ON, K7N 2X6

Attention: Michael Bardon
Alberta Research Council Fuels \& Lubricants

250 Kari Clark Road, Edmonton, Alberta, Canada T6N IE4

Certified by the Standards Council of Canada as an Accredited Testing Organization complying with the requirements of ISOIIEC 17025 for specific tests registered with the Council

\section{Report of Analysis}

This report may only be reproduced in its entirety
FUELS \& LUBRICANTS

INDUSTRIAL SUPPORT

Page 2 of 2

Report GO-2009-5204 to 5205

\begin{tabular}{|c|c|c|c|c|c|}
\hline $\begin{array}{l}\text { Lab Sample } \\
\text { Number }\end{array}$ & $\begin{array}{l}\text { Client's Reference } \\
\text { Sample Type; Date Received }\end{array}$ & Method & Analysis & Result & Notes \\
\hline \multirow[t]{19}{*}{ GO-2009-5205 } & $\begin{array}{l}\text { Non-oxygenates Winter Grade Gasoline } \\
\text { (M798) plus } 10 \% \text { vol. Commercial } \\
\text { Denatured Ethanol (GO-2009-4998) }\end{array}$ & & & & \\
\hline & Motor Gasoline; 24-Aug-2009 & & & & \\
\hline & & ASTM D86 & Distillation, \% Evaporated, ${ }^{\circ} \mathrm{C}$ (corrected) & & 1 \\
\hline & & & I.B.P. & 29.6 & \\
\hline & & & $5 \%$ & 37.1 & \\
\hline & & & $10 \%$ & 44.8 & \\
\hline & & & $20 \%$ & 57.7 & \\
\hline & & & $30 \%$ & 66.8 & \\
\hline & & & $40 \%$ & 71.7 & \\
\hline & & & $50 \%$ & 95.4 & \\
\hline & & & $60 \%$ & 103.8 & \\
\hline & & & $70 \%$ & 109.8 & \\
\hline & & & $80 \%$ & 118.6 & \\
\hline & & & $90 \%$ & 136.4 & \\
\hline & & & E.P. & 191.1 & \\
\hline & & & Residue, \% & 0.8 & \\
\hline & & & $\%$ Evaporated at $200^{\circ} \mathrm{F}$ & 49.3 & \\
\hline & & & $\%$ Evaporated at $300^{\circ} \mathrm{F}$ & 93.6 & \\
\hline & & ASTM D4052 & Density, kg/m?3 @ $15^{\circ} \mathrm{C}$ & 721.2 & 1 \\
\hline
\end{tabular}

Remarks and Notes

1 The commercial denatured ethanol used in blending this sample is composed of $95.16 \mathrm{vol} \%$ of ethanol, $4.44 \% \mathrm{vol}$ of ethanol denaturants and $0.40 \% \mathrm{vol}$ of water.

Signature:

Business Unit Manager

Date:

Phone: (780) 450-5108 email: wispinski@arc.ab.ca 


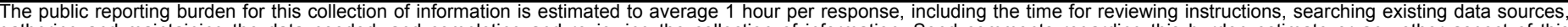

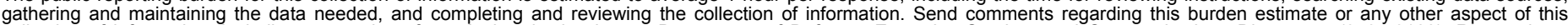

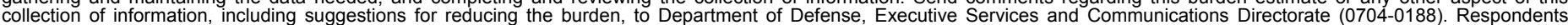

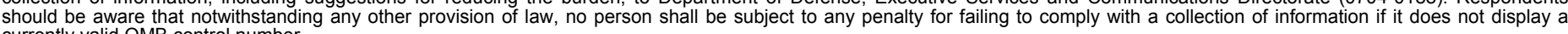

PLEASE DO NOT RETURN YOUR FORM TO THE ABOVE ORGANIZATION.

\section{REPORT DATE (DD-MM-YYYY) April 2010}

4. TITLE AND SUBTITLE

Experimental and Modeling Study of the Flammability of Fuel Tank Headspace Vapors from Ethanol/Gasoline Fuels, Phase 2:

Evaluations of Field Samples and Laboratory Blends
3. DATES COVERED (From - To) August 2005-December 2009

5a. CONTRACT NUMBER

DE-AC36-08-GO28308

5b. GRANT NUMBER

5c. PROGRAM ELEMENT NUMBER

5d. PROJECT NUMBER

NREL/SR-540-47819

5e. TASK NUMBER

FC080071

5f. WORK UNIT NUMBER
7. PERFORMING ORGANIZATION NAME(S) AND ADDRESS(ES)

Nexum Research Corporation

Kingston, Ontario, Canada

9. SPONSORING/MONITORING AGENCY NAME(S) AND ADDRESS(ES)

National Renewable Energy Laboratory

1617 Cole Blvd.

Golden, CO 80401-3393
8. PERFORMING ORGANIZATION REPORT NUMBER

Report No. 100101,

Subcontract No. XCl-5-55505-01

10. SPONSOR/MONITOR'S ACRONYM(S) NREL

11. SPONSORING/MONITORING AGENCY REPORT NUMBER NREL/SR-540-47819

12. DISTRIBUTION AVAILABILITY STATEMENT

National Technical Information Service

U.S. Department of Commerce

5285 Port Royal Road

Springfield, VA 22161

13. SUPPLEMENTARY NOTES

NREL Technical Monitor: W. Clark

14. ABSTRACT (Maximum 200 Words)

An experimental study measured the flammability of fuel vapors at low ambient temperatures and developed a mathematical model to predict the temperatures at which flammable vapors were likely to form. Results indicate that some currently available ethanol fuels are likely to produce flammable vapors within the ambient temperature range under Class 3 conditions. Results also indicate that mid-level ethanol blends (E20 and E30) are unlikely to significantly increase the risk of producing flammable vapors over that of the base gasoline used for the blends.

15. SUBJECT TERMS

ethanol; ethanol blends; fuel flammability studies; ethanol emissions; fuel tank vapors; gasoline vapors

16. SECURITY CLASSIFICATION OF:
\begin{tabular}{|l|l|l|}
\hline $\begin{array}{c}\text { a. REPORT } \\
\text { Unclassified }\end{array}$ & $\begin{array}{c}\text { b. ABSTRACT } \\
\text { Unclassified }\end{array}$ & $\begin{array}{c}\text { c. THIS PAGE } \\
\text { Unclassified }\end{array}$ \\
\hline
\end{tabular}

19a. NAME OF RESPONSIBLE PERSON

19b. TELEPHONE NUMBER (Include area code) 